\title{
Safety of checkpoint inhibitors for cancer treatment: strategies for patient monitoring and management of immune-mediated adverse events
}

This article was published in the following Dove Press journal:

ImmunoTargets and Therapy

24 August 2017

Number of times this article has been viewed

Marianne Davies ${ }^{1-3}$

Emily A Duffield ${ }^{3}$

'Yale School of Nursing, ${ }^{2}$ Department of Medical Oncology, Yale Comprehensive Cancer Center, ${ }^{3}$ Department of Nursing, Smilow Cancer Hospital at Yale-New Haven Hospital, New Haven, CT, USA

\section{Video abstract}

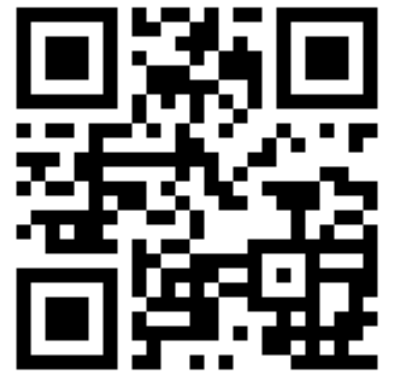

Point your SmartPhone at the code above. If you have a $Q R$ code reader the video abstract will appear. Or use: http://youtu.be/QtChTQdxCCc
Correspondence: Marianne Davies Yale School of Nursing, Acute Care \& DNP Division, PO Box 27399, West

Haven, CT 06516-0972, USA

$\mathrm{Tel}+\mid 203737$ |497

Fax + I 2037374480

Email marianne.davies@yale.edu
Abstract: Immune checkpoint inhibitors (ICPIs), in the form of monoclonal antibodies against CTLA-4, PD-1, and PD-L1, have dramatically changed the treatment approach in several advanced cancers. Due to their mechanism of action, these novel agents are associated with a unique spectrum of immune-mediated adverse events (imAEs), with a safety profile that indicates they are better tolerated than traditional chemotherapeutic agents. This article aims to provide education on the current knowledge about imAEs associated with ICPI treatment, including strategies and tools for the prompt identification, evaluation, and optimal management of these events. The identification and management of imAEs are reviewed based on published literature, labeling guidelines, and the authors' personal experience with patients. The imAE safety profiles of ICPIs vary, depending on the specific antibody and the type of cancer being treated. Although most imAEs are mild and easily managed, early identification and proactive treatment are essential actions serving both to reduce the risk of developing severe imAEs and to maximize the potential for patients to receive the benefits of ongoing ICPI treatment. As a primary point of contact for patients undergoing oncology treatment, nurses play a critical role in identifying imAEs, educating patients about the importance of timely reporting of potentially relevant symptoms, and assisting in the treatment and follow-up of patients who develop imAEs while on ICPI therapy.

Keywords: immune-mediated adverse event, checkpoint inhibitor, immunotherapy, CTLA-4, PD-1, PD-L1

\section{Introduction}

Harnessing the power of a patient's immune system to attack cancer cells has become a reality. In recent years, immune checkpoint inhibitors (ICPIs) have emerged as a new class of drugs capable of augmenting the body's immune response against several different tumor types. ${ }^{1-21}$ ICPIs approved by the US Food and Drug Administration (FDA) include monoclonal antibodies against CTLA-4 (ipilimumab ${ }^{22}$ ), PD-1 (nivolumab, ${ }^{23}$ pembrolizumab ${ }^{24}$ ), and, most recently, PD-L1 (atezolizumab, ${ }^{25}$ avelumab, ${ }^{26}$ and durvalumab $^{27}$ ). Additional indications are being explored for approved agents, ${ }^{28-34}$ and other ICPIs are in late-stage development, including a new anti-CTLA-4 antibody (tremelimumab; Table 1). ${ }^{35}$ Furthermore, combination anti-CTLA-4 and anti-PD-L1 antibody therapy (ipilimumab + nivolumab) was recently added to the National Comprehensive Cancer Network Guidelines as a second-line treatment for small cell lung cancer, ${ }^{36}$ and many combinations are in development.

ICPIs are monoclonal antibodies targeting CTLA-4, PD-1, or PD-L1, checkpoint proteins known to prevent excessive immune response. ICPIs can influence the body's 
immune response against tumor cells by revitalizing suppressed immune cells, hence promoting an antitumor immune response. CTLA-4 and PD-1/PD-L1 are nonredundant T-cell activation checkpoint pathways, acting at different stages of the antitumor immune response. CTLA-4 is primarily involved in the early stages of T-cell activation within the

Table I ICPIs approved or in late-stage development ${ }^{\mathrm{a}}$

\begin{tabular}{|c|c|c|c|c|c|}
\hline Agent & \multicolumn{3}{|l|}{ Tumor type } & ORR (\%) & Approved (dose)/stage of development \\
\hline \multicolumn{6}{|c|}{ Anti-CTLA-4 monotherapy } \\
\hline \multirow[t]{2}{*}{ Ipilimumab } & \multicolumn{3}{|c|}{ Melanoma - unresectable or metastatic (IL+) } & $I^{22, b}$ & Approved ${ }^{22}$ ( $3 \mathrm{mg} / \mathrm{kg} \mathrm{q3w}$, up to four doses) \\
\hline & \multicolumn{3}{|c|}{$\begin{array}{l}\text { Melanoma with pathologic involvement of regional lymph nodes } \\
\text { - adjuvant }\end{array}$} & $49^{22, c}$ & $\begin{array}{l}\text { Approved } 22 \text { ( } 10 \mathrm{mg} / \mathrm{kg} \mathrm{q} 3 \mathrm{w} \text {, up to four doses, } \\
\text { then } \mathrm{q} 12 \mathrm{w} \text { up to } 3 \text { years })\end{array}$ \\
\hline \multicolumn{6}{|c|}{ Anti-PD-I monotherapy } \\
\hline \multirow[t]{14}{*}{ Nivolumab } & \multirow{3}{*}{$\begin{array}{l}\text { Melanoma - unresectable or } \\
\text { metastatic }^{d}\end{array}$} & \multirow[t]{2}{*}{ IL } & BRAF wt & $34^{23}$ & \multirow[t]{7}{*}{ Approved $^{23}(240 \mathrm{mg} \mathrm{q} 2 \mathrm{w})$} \\
\hline & & & BRAF wt and BRAF mut+ & $40^{23}$ & \\
\hline & & $2 \mathrm{~L}+$ & & $32^{23}$ & \\
\hline & \multirow[t]{2}{*}{ NSCLC - metastatic (2L) } & Squ & imous & $20^{23}$ & \\
\hline & & No & isquamous & $19^{23}$ & \\
\hline & \multicolumn{3}{|c|}{ Renal cell carcinoma - advanced (2L) } & $22^{23}$ & \\
\hline & \multicolumn{3}{|c|}{$\begin{array}{l}\text { Urothelial carcinoma - locally advanced or metastatic ( } 2 \mathrm{~L} \text { or IL } \\
\text { after neoadjuvant/adjuvant chemotherapy) }\end{array}$} & $20^{23}$ & \\
\hline & \multicolumn{3}{|c|}{ HNSCC - recurrent or metastatic (2L) } & $13^{23}$ & Approved $^{23}(3 \mathrm{mg} / \mathrm{kg} \mathrm{q} 2 \mathrm{w})$ \\
\hline & \multirow[t]{2}{*}{$\begin{array}{l}\text { Classical Hodgkin lymphoma - } \\
\text { relapsed or refractory }\end{array}$} & \multicolumn{2}{|c|}{$\begin{array}{l}2 \mathrm{~L} \text {, after HSCT and } \\
\text { brentuximab vedotin therapy }\end{array}$} & $66^{23}$ & \\
\hline & & \multicolumn{2}{|c|}{$4 \mathrm{~L}+$, including prior $\mathrm{HSCT}^{\mathrm{e}}$} & $69^{23}$ & \\
\hline & \multicolumn{3}{|l|}{ Glioblastoma } & - & Phase III: CheckMate I43 (NCT020177/7) \\
\hline & \multicolumn{3}{|l|}{ HCC - advanced (IL) } & - & Phase III: CheckMate 459 (NCT02576509) \\
\hline & \multicolumn{3}{|c|}{$\begin{array}{l}\text { Gastric cancer and gastroesophageal junction cancer - } \\
\text { unresectable advanced or recurrent }\end{array}$} & - & Phase III: NCT02267343 \\
\hline & \multicolumn{3}{|l|}{ SCLC - relapsed (2L) } & - & Phase III: CheckMate 33I (NCT0248I830) \\
\hline \multirow[t]{12}{*}{ Pembrolizumab $^{f}$} & \multirow{2}{*}{$\begin{array}{l}\text { Melanoma - unresectable or } \\
\text { metastatic }\end{array}$} & \multicolumn{2}{|l|}{ IL } & $33^{24}$ & \multirow[t]{2}{*}{ Approved $^{24}(2 \mathrm{mg} / \mathrm{kg} \mathrm{q3w})$} \\
\hline & & Ipili & numab-refractory & $21^{24}$ & \\
\hline & \multirow[t]{2}{*}{ NSCLC (PD-LI+) - metastatic } & \multicolumn{2}{|c|}{ IL PD-LI+ (high levels) } & $45^{24}$ & \multirow[t]{5}{*}{ Approved $^{24}\left(200 \mathrm{mg} \mathrm{q}^{3} \mathrm{w}\right)$} \\
\hline & & $2 \mathrm{~L}$, & PD-LI+ & $18^{24}$ & \\
\hline & \multicolumn{3}{|c|}{ HNSCC - recurrent or metastatic (2L)e } & $16^{24}$ & \\
\hline & Urothelial carcinoma - locally & $\mathrm{IL} \mathrm{i}$ & cisplatin-ineligible ${ }^{e}$ & 2924 & \\
\hline & advanced or metastatic & $\begin{array}{l}2 L \\
\text { adju }\end{array}$ & $\begin{array}{l}\text { IL after neoadjuvant/ } \\
\text { vant chemotherapy }\end{array}$ & $21^{24}$ & \\
\hline & $\begin{array}{l}\text { Classical Hodgkin lymphoma }-r \\
\text { of prior HSCT or brentuximab }\end{array}$ & lapse & $\begin{array}{l}\text { or refractory, regardless } \\
\text { therapy }(4 \mathrm{~L}+)^{\mathrm{e}}\end{array}$ & $69^{24}$ & $\begin{array}{l}\text { Approved } 24,103(200 \mathrm{mg} \text { q3w [adults]; } \\
2 \mathrm{mg} / \mathrm{kg} \text { [up to } 200 \mathrm{mg} \text { ] q3w [pediatrics]) }\end{array}$ \\
\hline & $\begin{array}{l}\text { MSI-H or AMMR solid tumor - } \\
\text { with no satisfactory alternative }\end{array}$ & rese & $\begin{array}{l}\text { table or metastatic }(2 \mathrm{~L}+) \\
\text { ent options }\end{array}$ & $40^{24}$ & \\
\hline & $\begin{array}{l}\text { MSI-H or DMMR CRC - unrese } \\
\text { treatment with fluoropyrimidine }\end{array}$ & $\begin{array}{l}\text { able } \\
\text { oxal }\end{array}$ & $\begin{array}{l}\text { or metastatic }(2 \mathrm{~L}+\text {, after } \\
\text { Dlatin, and irinotecan) }\end{array}$ & $36^{24}$ & \\
\hline & TNBC - metastatic ( $2 \mathrm{~L}$ and $3 \mathrm{~L}$ ) & & & - & Phase III: KEYNOTE-I I 9 (NCT02555657) \\
\hline & $\begin{array}{l}\text { Gastric/gastroesophageal junctic } \\
\text { unresectable, locally advanced, }\end{array}$ & ade & $\begin{array}{l}\text { locarcinoma - } \\
\text { istatic (2L) }\end{array}$ & - & Phase III: KEYNOTE-06I (NCT02370498) \\
\hline Anti-PD-LI mon & otherapy & & & & \\
\hline Atezolizumab & Urothelial carcinoma - locally & $\mathrm{IL} \mathrm{i}$ & cisplatin-ineligible $^{c}$ & $24^{25}$ & Approved $^{25}(1200 \mathrm{mg} \mathrm{q3w})$ \\
\hline & advanced or metastatic & $\begin{array}{l}2 L \\
\text { adji }\end{array}$ & $\begin{array}{l}\text { IL after neoadjuvant/ } \\
\text { vant chemotherapy }\end{array}$ & $15^{25}$ & \\
\hline & NSCLC - metastatic (2L) & & & $14^{13}-15^{25}$ & \\
\hline
\end{tabular}


Table I (Continued)

\begin{tabular}{|c|c|c|c|c|}
\hline Agent & \multicolumn{2}{|l|}{ Tumor type } & ORR (\%) & Approved (dose)/stage of development \\
\hline \multirow[t]{5}{*}{ Avelumab } & \multicolumn{2}{|c|}{ Merkel cell carcinoma - metastatic ${ }^{\mathrm{e}}$} & $33^{26}$ & \multirow[t]{2}{*}{ Approved $^{26}(10 \mathrm{mg} / \mathrm{kg} \mathrm{q2w})$} \\
\hline & \multicolumn{2}{|c|}{$\begin{array}{l}\text { Urothelial carcinoma - locally advanced or metastatic ( } 2 \mathrm{~L} \text { or IL } \\
\text { after neoadjuvant/adjuvant chemotherapy) }\end{array}$} & $13^{26}$ & \\
\hline & \multicolumn{2}{|c|}{$\begin{array}{l}\text { Gastric or gastroesophageal cancer - unresectable, locally } \\
\text { advanced, or metastatic (3L) }\end{array}$} & - & Phase III: JAVELIN Gastric 300 (NCT02625623) \\
\hline & \multicolumn{2}{|c|}{ NSCLC (PD-LI+) - locally advanced or metastatic (2L) } & - & Phase III: JAVELIN Lung 200 (NCT02395I72) \\
\hline & \multicolumn{2}{|c|}{ Ovarian cancer - platinum resistant/refractory $(2-4 L)$} & - & Phase III: JAVELIN Ovarian 200 (NCT02580058) \\
\hline \multirow[t]{4}{*}{ Durvalumab } & \multicolumn{2}{|c|}{$\begin{array}{l}\text { Urothelial carcinoma - locally advanced or metastatic ( } 2 \mathrm{~L} \text { or IL } \\
\text { after neoadjuvant/adjuvant chemotherapy) }^{\mathrm{e}}\end{array}$} & $17^{27}$ & Approved $^{27}(10$ mg/kg q2w) \\
\hline & \multicolumn{2}{|c|}{ Urothelial carcinoma - unresectable (IL) } & - & Phase III: DANUBE (NCT025I624I) \\
\hline & \multicolumn{2}{|c|}{$\begin{array}{l}\text { NSCLC - unresectable Stage III, locally advanced, or metastatic } \\
\text { (IL and } 3 L \text { ) }\end{array}$} & - & $\begin{array}{l}\text { Phase III: PACIFIC (NCT02 I 2546I), MYSTIC } \\
\text { (NCT02453282), ARCTIC (NCT02352948) }\end{array}$ \\
\hline & \multicolumn{2}{|c|}{ HNSCC - recurrent/metastatic (IL and $2 \mathrm{~L}$ ) } & - & $\begin{array}{l}\text { Phase III: KESTREL (NCT0255 I I 59), EAGLE } \\
\text { (NCT02369874); FDA fast-track designation }{ }^{104}\end{array}$ \\
\hline \multicolumn{5}{|c|}{ Combination anti-CTLA-4 + anti-PD-I/PD-LI } \\
\hline \multirow{5}{*}{$\begin{array}{l}\text { Nivolumab }+ \\
\text { ipilimumab }\end{array}$} & \multirow{2}{*}{$\begin{array}{l}\text { Melanoma - unresectable or } \\
\text { metastatic }(I \mathrm{~L}+)^{\mathrm{e}}\end{array}$} & BRAF wt & $61^{105}$ & \multirow{2}{*}{$\begin{array}{l}\text { Approved }{ }^{23} \text { (nivolumab I mg/kg + ipilimumab } \\
3 \mathrm{mg} / \mathrm{kg} \mathrm{q}^{2} \mathrm{w} \text { for four doses, then nivolumab } \\
240 \mathrm{mg} \mathrm{q} 2 \mathrm{w} \text { ) }\end{array}$} \\
\hline & & BRAF wt and BRAF mut+ & $50^{23}$ & \\
\hline & \multicolumn{2}{|c|}{ SCLC - extensive-stage disease $(2 \mathrm{~L})$} & - & $\begin{array}{l}\text { Phase III: CheckMate } 45 \text { I (NCT02538666); } \\
\text { NCCN recommendation }{ }^{36}\end{array}$ \\
\hline & \multicolumn{2}{|c|}{ NSCLC - advanced (IL or recurrent) } & - & Phase III: CheckMate 227 (NCT02477826) \\
\hline & \multicolumn{2}{|l|}{ Glioblastoma } & - & Phase III: CheckMate I43 (NCT020177I7) \\
\hline \multirow[t]{3}{*}{$\begin{array}{l}\text { Durvalumab + } \\
\text { tremelimumab }\end{array}$} & \multicolumn{2}{|c|}{ NSCLC - locally advanced or metastatic (IL and 3L) } & - & $\begin{array}{l}\text { Phase III: MYSTIC (NCT02453282), ARCTIC } \\
\text { (NCT02352948) }\end{array}$ \\
\hline & \multicolumn{2}{|c|}{ HNSCC - recurrent/metastatic (IL and $2 \mathrm{~L}$ ) } & - & $\begin{array}{l}\text { Phase III: KESTREL (NCT0255 I I59), EAGLE } \\
\text { (NCT02369874) }\end{array}$ \\
\hline & \multicolumn{2}{|c|}{ Urothelial carcinoma - unresectable (IL) } & - & Phase III: DANUBE (NCT025I624I) \\
\hline
\end{tabular}

Notes: aLate-stage development refers to Phase III sponsored studies that expect to have primary results on or before QI 2018 in tumor types different from those in which the agents are already approved. ${ }^{b}$ Best overall response rate. ${ }^{\mathrm{C}}$ Recurrence-free survival rate. ${ }^{\mathrm{d} A c c e l e r a t e d}$ approval for BRAF V600 mutation-positive unresectable/metastatic melanoma; continued approval may be contingent on confirmatory trials. ${ }^{\mathrm{e} A c c e l e r a t e d ~ a p p r o v a l ; ~ c o n t i n u e d ~ a p p r o v a l ~ m a y ~ b e ~ c o n t i n g e n t ~ o n ~ c o n f i r m a t o r y ~ t r i a l s . ~}{ }^{.}$Pembrolizumab is also approved in combination with pemetrexed and carboplatin as IL treatment for metastatic nonsquamous NSCLC (ORR, $55 \%$ ). ${ }^{24}$ 8Tremelimumab is an anti-CTLA-4 monoclonal antibody currently in late-stage studies in combination with durvalumab.

Abbreviations: IL, first line; 2L, second line; 3L, third line; 4L, fourth line; CRC, colorectal cancer; dMMR, mismatch repair-deficient; HCC, hepatocellular carcinoma; HNSCC, head and neck squamous cell carcinoma; HSCT, hematopoietic stem cell transplant; ICPIs, immune checkpoint inhibitors; MSI-H, microsatellite instability-high cancer; NSCLC, non-small cell lung cancer; ORR, objective response rate; q2w, every 2 weeks; q3w, every 3 weeks; q12w, every 12 weeks; SCLC, small cell lung cancer; TNBC, triple-negative breast cancer; wt, wild type; mut, mutant; -, not available.

lymph node, whereas the PD-1/PD-L1 pathway acts at late stages of the antitumor immune response within the tumor microenvironment. Therefore, targeting both checkpoints provides the potential for additive or synergistic effects. ${ }^{37,38}$

ICPIs have improved the prognosis for patients with advanced melanoma, ${ }^{2,4,9,39-42}$ non-small cell lung cancer (NSCLC), ${ }^{6,11,13,16,21,43,44}$ renal cell carcinoma, ${ }^{5}$ urothelial carcinoma, ${ }^{7,8,15,18-20}$ Hodgkin's lymphoma, ${ }^{14,45}$ head and neck squamous cell carcinoma, ${ }^{3,12}$ Merkel cell carcinoma, ${ }^{10}$ and microsatellite instability - high or mismatch repair-deficient cancer. ${ }^{1}$ Given the current success of ICPIs in an increasingly wide range of tumor types, the approved indications for ICPIs are expected to increase. In fact, ICPIs have shown promising efficacy in clinical studies in many other cancer types including small cell lung cancer, ${ }^{31}$ hepatic cancer, ${ }^{33}$ triple-negative breast cancer, ${ }^{28}$ ovarian cancer, ${ }^{32}$ colorectal cancer, ${ }^{46}$ gastric cancer, ${ }^{29}$ and glioblastoma. ${ }^{30}$

Due to their novel mechanism of action, ICPIs are associated with a spectrum of immune-mediated adverse events (imAEs) that differ from the typical adverse events seen with chemotherapeutic agents. ${ }^{47,48}$ By inhibiting the checkpoints for T-cell activation, ICPIs can cause the patient's immune system to recognize and attack tumor cells. However, this deregulation of the immune system may also lead to immunemediated toxicities, which can mimic a broad range of autoimmune conditions. ${ }^{49}$ By understanding the signs and symptoms of these unique adverse events, oncology nurses will be better equipped to educate, monitor, and manage cancer patients receiving ICPIs. This article reviews the imAE profile of anti-CTLA-4 and anti-PD-1/PD-L1 anti- 
bodies, including an approach for monitoring patients and managing the imAEs associated with this new and growing therapeutic class.

\section{Dosing of ICPIs}

Dosage recommendations for ICPIs include both weightbased and fixed doses (Table 1). ${ }^{22-27}$ Although imAE risk appears to be greater with the higher dose of anti-CTLA-4 therapy (ipilimumab $10 \mathrm{mg} / \mathrm{kg}$ ) than with the lower dose (ipilimumab $3 \mathrm{mg} / \mathrm{kg}$ ), ${ }^{22}$ a similar dose effect on toxicity has not been observed in clinical studies of the currently marketed anti-PD-1 antibodies (nivolumab, pembrolizumab). ${ }^{50-53}$ Available safety data are based on registration studies that included varying dosing regimens for pembrolizumab (2 mg/ $\mathrm{kg}$ or $10 \mathrm{mg} / \mathrm{kg}$ every 2 or 3 weeks) ${ }^{24}$ and weight-based dosing for nivolumab ( $3 \mathrm{mg} / \mathrm{kg})$, which was the recommended dose until September 2016 when a $240 \mathrm{mg}$ fixed dose was deemed to provide a similar drug exposure. ${ }^{23,53}$ Clinical registration studies of anti-PD-L1 antibodies utilized the current recommended doses (atezolizumab $1200 \mathrm{mg},{ }^{25}$ avelumab $10 \mathrm{mg} / \mathrm{kg},{ }^{26}$ and durvalumab $\left.10 \mathrm{mg} / \mathrm{kg}^{27}\right)$. Combination antiCTLA-4 and anti-PD-1 therapy is currently dosed as sameday ipilimumab (3 $\mathrm{mg} / \mathrm{kg}$ ) followed by nivolumab (1 mg/ $\mathrm{kg}$ ) every 3 weeks for four doses, followed by nivolumab (240 mg) every 2 weeks thereafter. ${ }^{23}$ As this combination regimen is associated with greater toxicity than ICPI monotherapy, ${ }^{22-26}$ alternative dosing strategies are being evaluated in clinical studies with the objective of improving the safety/ efficacy profile, including lower-dose anti-CTLA-4 antibodies in combination with anti-PD-1/anti-PD-L1 antibodies (nivolumab + ipilimumab, ${ }^{54}$ pembrolizumab + ipilimumab,${ }^{55}$ durvalumab + tremelimumab ${ }^{56}$ ). Unlike chemotherapy where it is typical to dose-reduce patients to manage toxicities, the only dose modifications currently allowed with ICPIs are to either delay or discontinue therapy. Therefore, establishing the optimal dosing regimen of checkpoint inhibitors is very important.

\section{imAEs}

Typically, imAEs associated with ICPI treatment are low grade and manageable when identified promptly and treated properly. ${ }^{57,58}$ In clinical studies reporting the overall rate of imAEs, imAEs occurred in up to $90 \%$ of patients receiving ICPI monotherapy (Table 2). 4,7,9,10,16-18,20,39,40,43,59,60 However, the incidence of high-grade (Grade $\geq 3$ ) imAEs in these studies was generally much lower, especially with anti-PD-1 or PD-L1 antibodies. Notably, Grade $\geq 3$ imAEs were reported to occur more frequently in patients receiving anti-CTLA-4 monotherapy (ipilimumab, 15-42\%) ) $^{4,939,40}$ than in those receiving anti-PD-1 (8\%, nivolumab; ${ }^{4} 5-10 \%$, pembrolizumab $\left.^{16,20}\right)$ or anti-PD-L1 (5-7\%, atezolizumab; ; 17 , durvalumab, ${ }^{59} 1-2 \%$, avelumab ${ }^{10,61}$ ) monotherapy, and the highest rate of Grade $\geq 3$ imAEs was reported with combination anti-CTLA-4 and anti-PD-1 therapy (ipilimumab + nivolumab, 40-45\%). ${ }^{4,9}$ The skin and gastrointestinal tract are the most common sites for imAEs with any of the approved ICPIs, either in monotherapy or in combination, although any organ system can be affected (Table 3 ). ${ }^{57}$ In this section, we highlight the five most common organ systems affected by imAEs in patients treated with ICPIs: dermatologic, gastrointestinal, endocrine, hepatic, and pulmonary. Less common but clinically important manifestations of imAEs are also briefly reviewed (renal, pancreatic, ocular, musculoskeletal, neurological, cardiovascular, and hematological toxicities).

\section{Dermatologic}

Rash and pruritus are the most common dermatological adverse events observed in patients receiving ICPI therapy, occurring more frequently with anti-CTLA-4 therapy (ipilimumab: $3 \mathrm{mg} / \mathrm{kg}$ [rash, 15-30\%; pruritus, 24-35\%]; ;,9,39,42 $10 \mathrm{mg} / \mathrm{kg}$ [rash, 34\%; pruritus, 40\%] ${ }^{40}$ ) than with anti-PD-1 (nivolumab/pembrolizumab: rash, 4-22\%; pruritus, 2-23\%) $2,4,6,11,15,16,41-43,50,51,62$ or anti-PD-L1 treatment (atezolizumab/avelumab/durvalumab: rash, 1-7\%; pruritus, 1-11\%). ${ }^{7,10,13,17,59-61}$ Skin toxicities are typically low grade, often presenting as erythematous macules/papules/plaques on the trunk or extremities with or without pruritus during the early weeks of treatment (Figure 1). ${ }^{57,63,64}$ Dermatologic toxicities have been observed more often in patients receiving ICPIs for melanoma than for NSCLC (Table 2). 2,4,6,9,11,13,16,41-43,50,51,65,66 Vitiligo may occur more frequently in patients receiving antiPD-1 antibodies (nivolumab/pembrolizumab, 7-11\%) than with anti-CTLA-4 therapy (ipilimumab, 2-4\%).,42 Grade 3/4 skin imAEs are rare, although cases of Stevens-Johnson syndrome and toxic epidermal necrolysis have been reported in patients receiving anti-CTLA-4 (ipilimumab) ${ }^{22,57}$ or antiPD-1 treatments (nivolumab/pembrolizumab). ${ }^{23,67}$

\section{Gastrointestinal}

Diarrhea is the most common gastrointestinal adverse event, occurring in $23-41 \%$ of patients treated with antiCTLA-4 (ipilimumab: $3 \mathrm{mg} / \mathrm{kg}, 23-35 \%$; $10 \mathrm{mg} / \mathrm{kg}$, $41 \%), 4,9,39,40,427-19 \%$ of patients treated with anti-PD-1 antibodies (nivolumab, 8-19\%; ;,6,11,15,41,62 pembrolizumab, $\left.7-16 \%{ }^{2,16,42,43,50,51}\right), 2-15 \%$ of patients receiving anti-PD-L1 therapy (atezolizumab, 7-15\%; ${ }^{7,13,17,44}$ avelumab, <1-9\%; ${ }^{10,61}$ 


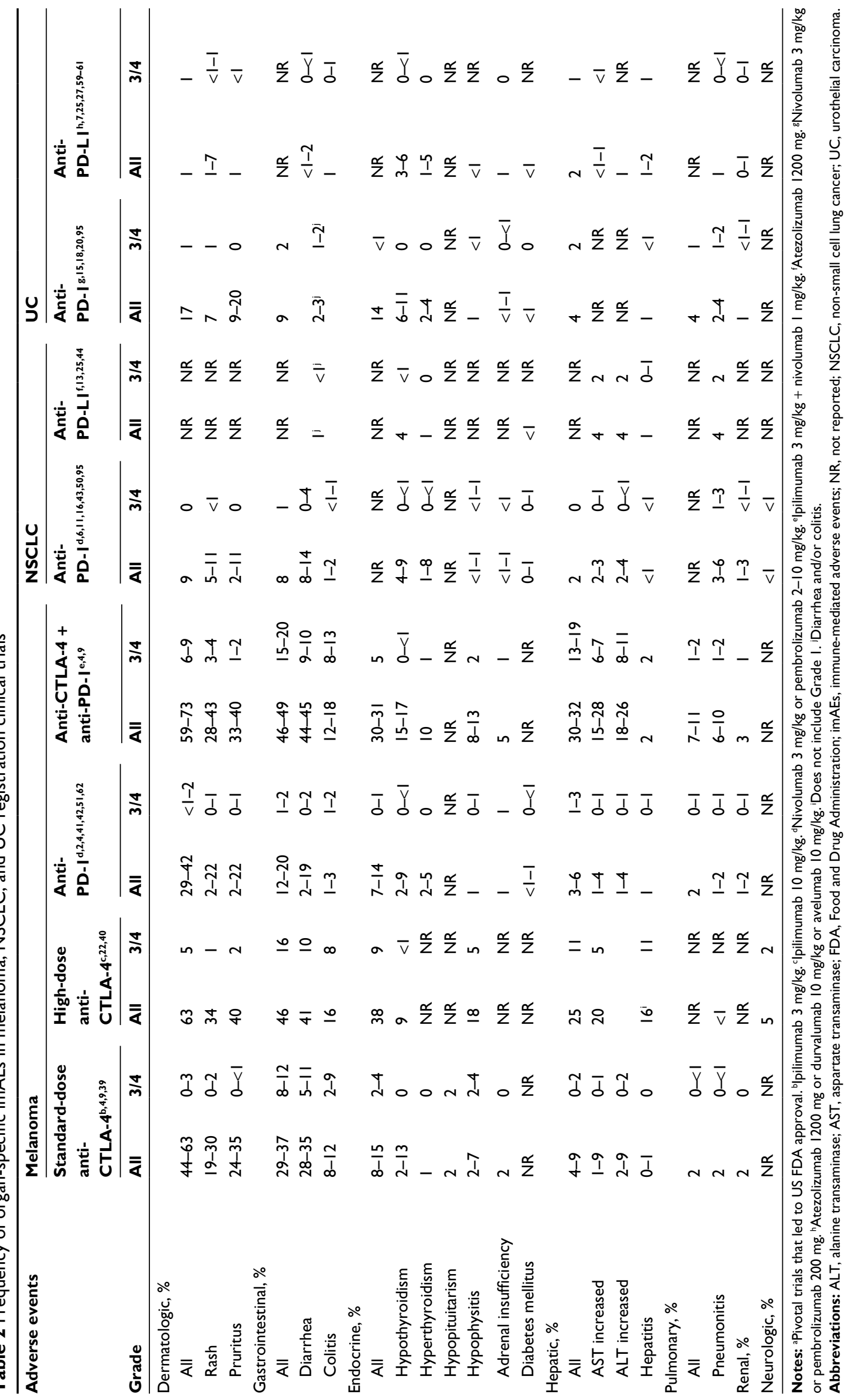




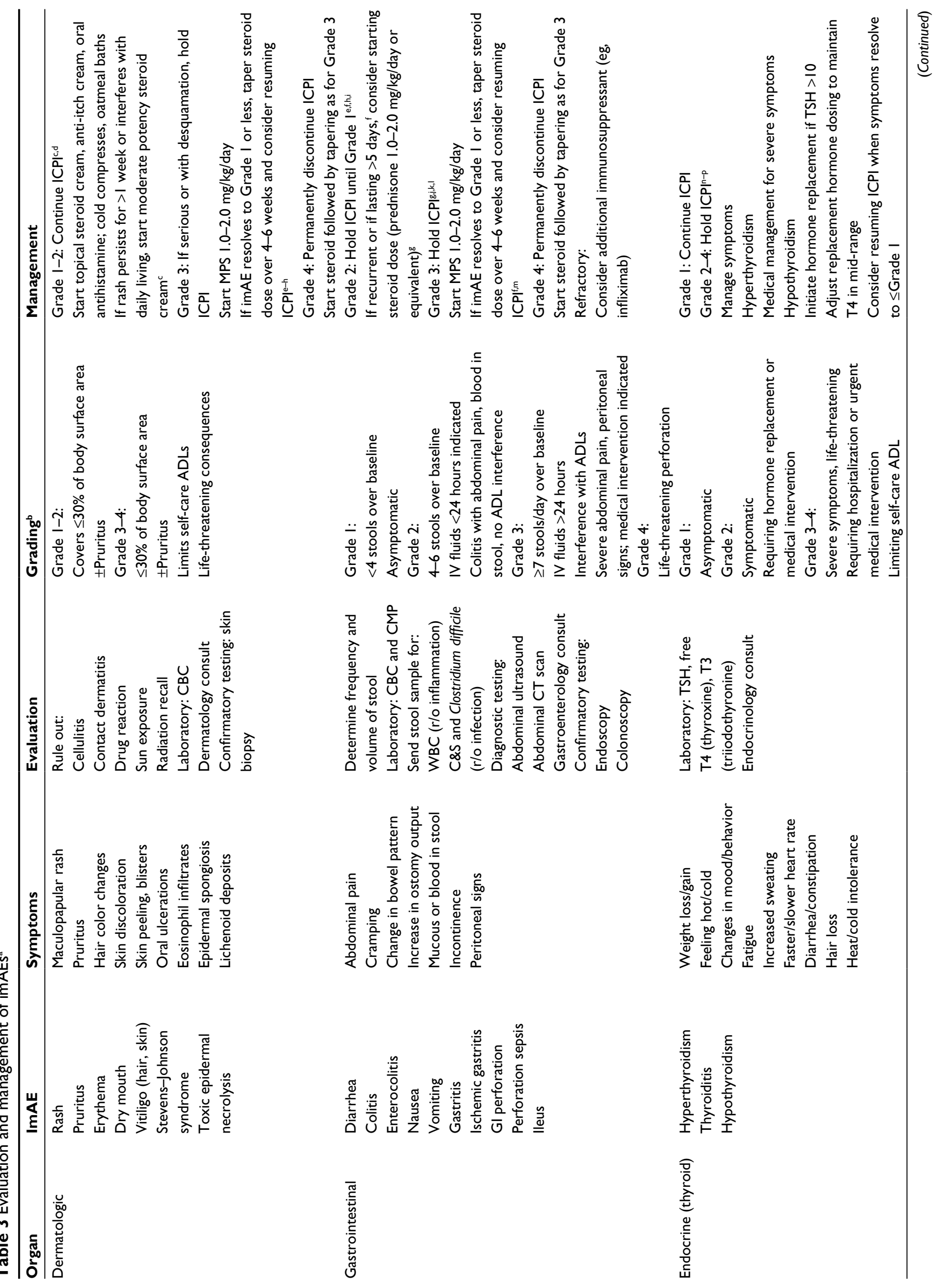




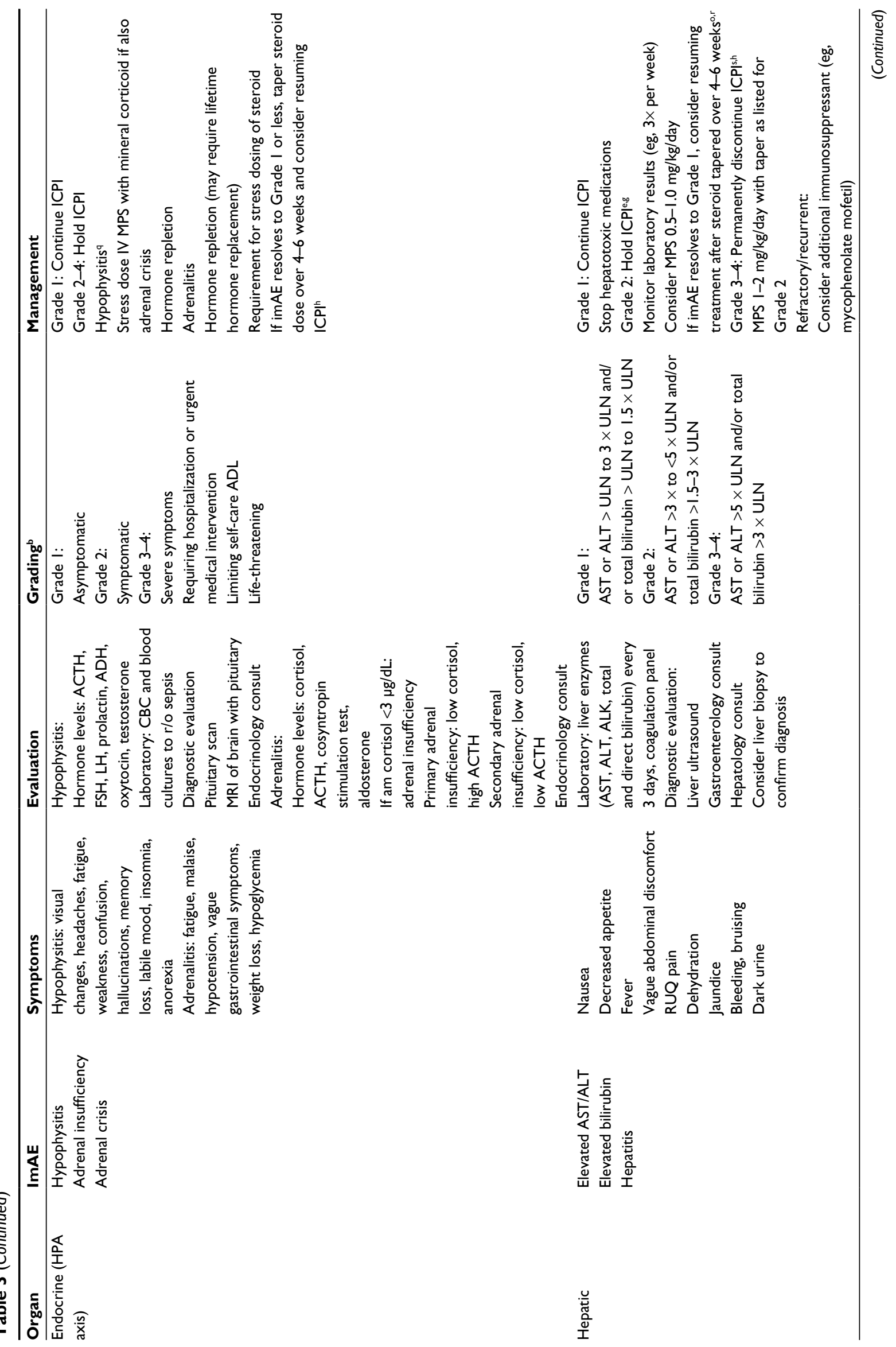




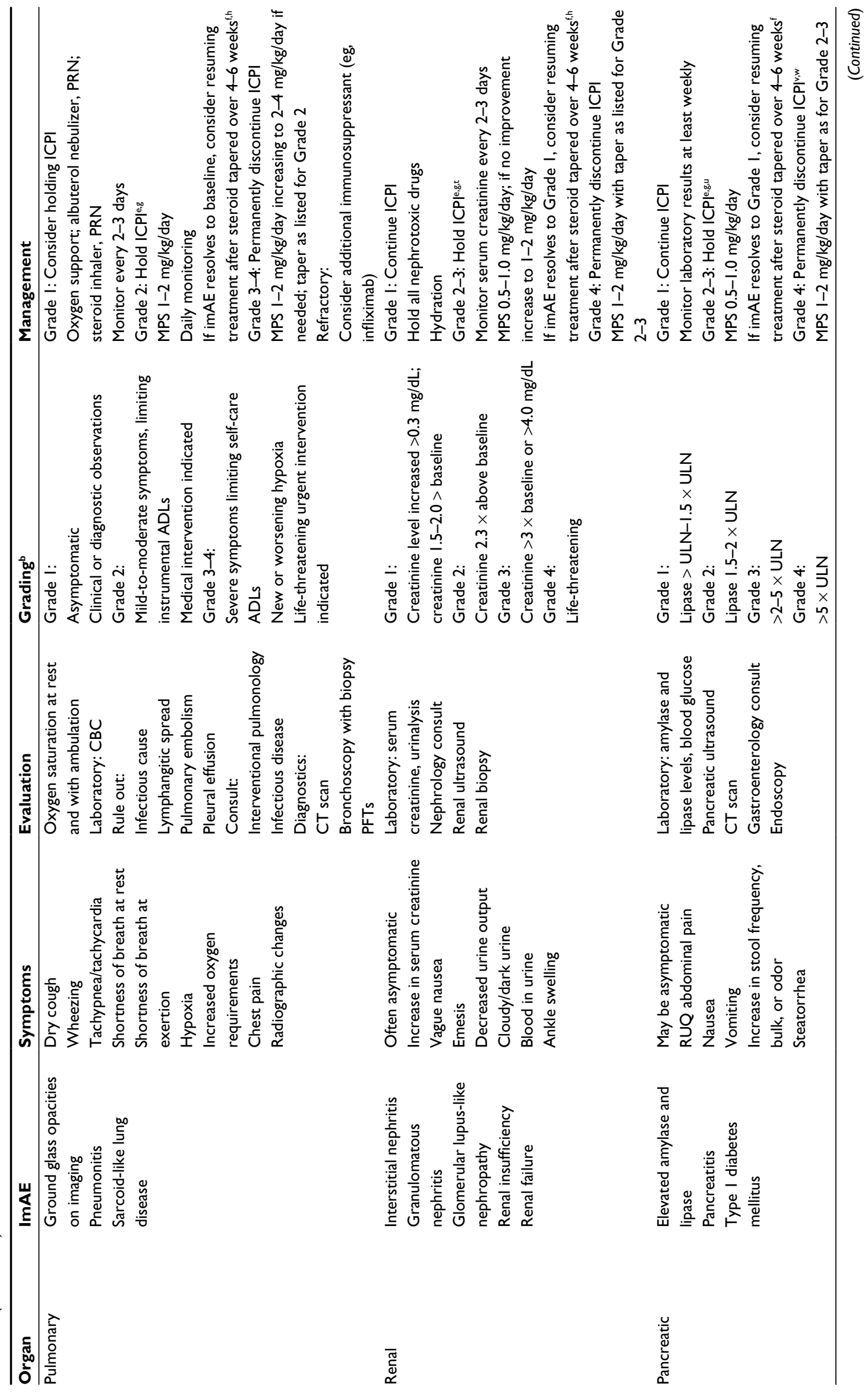




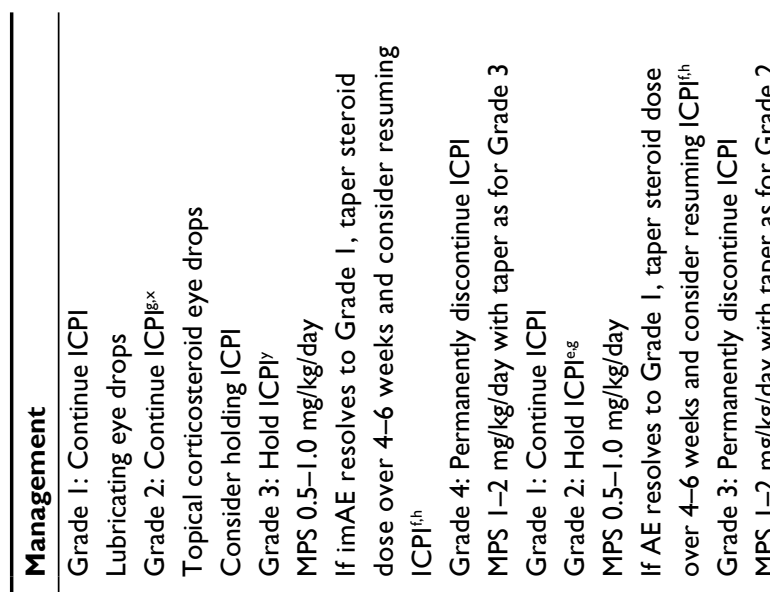

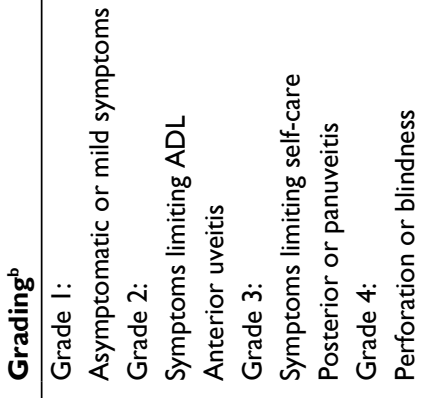
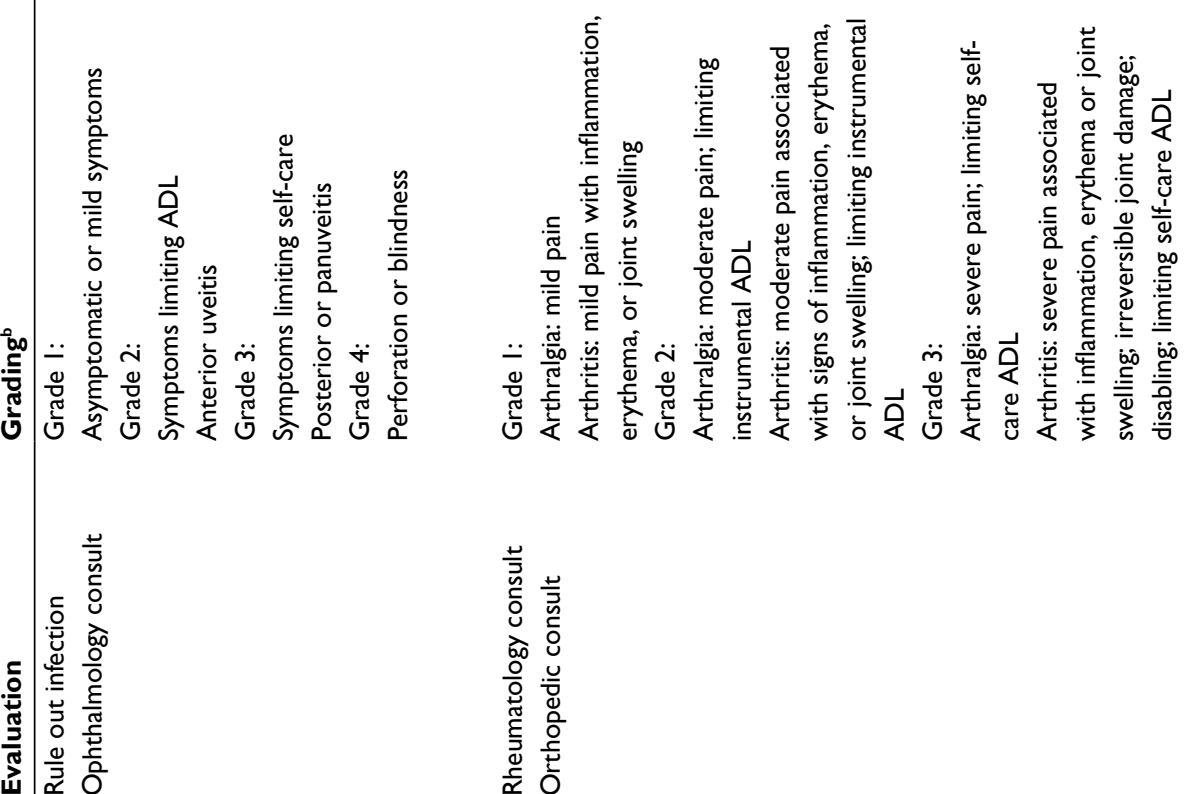

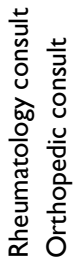
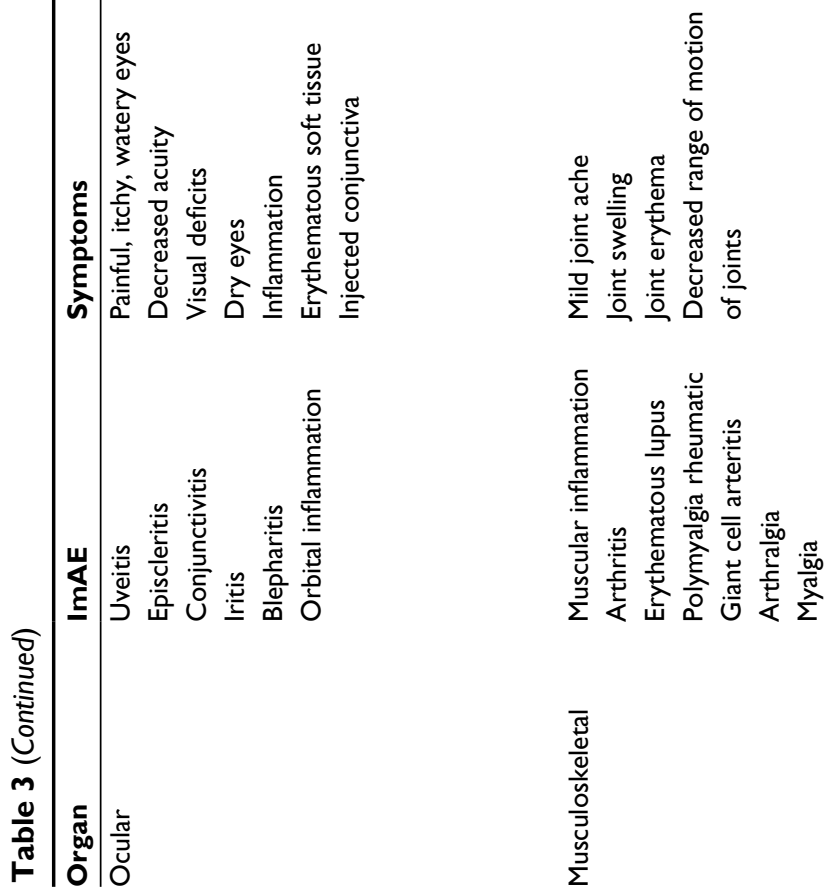


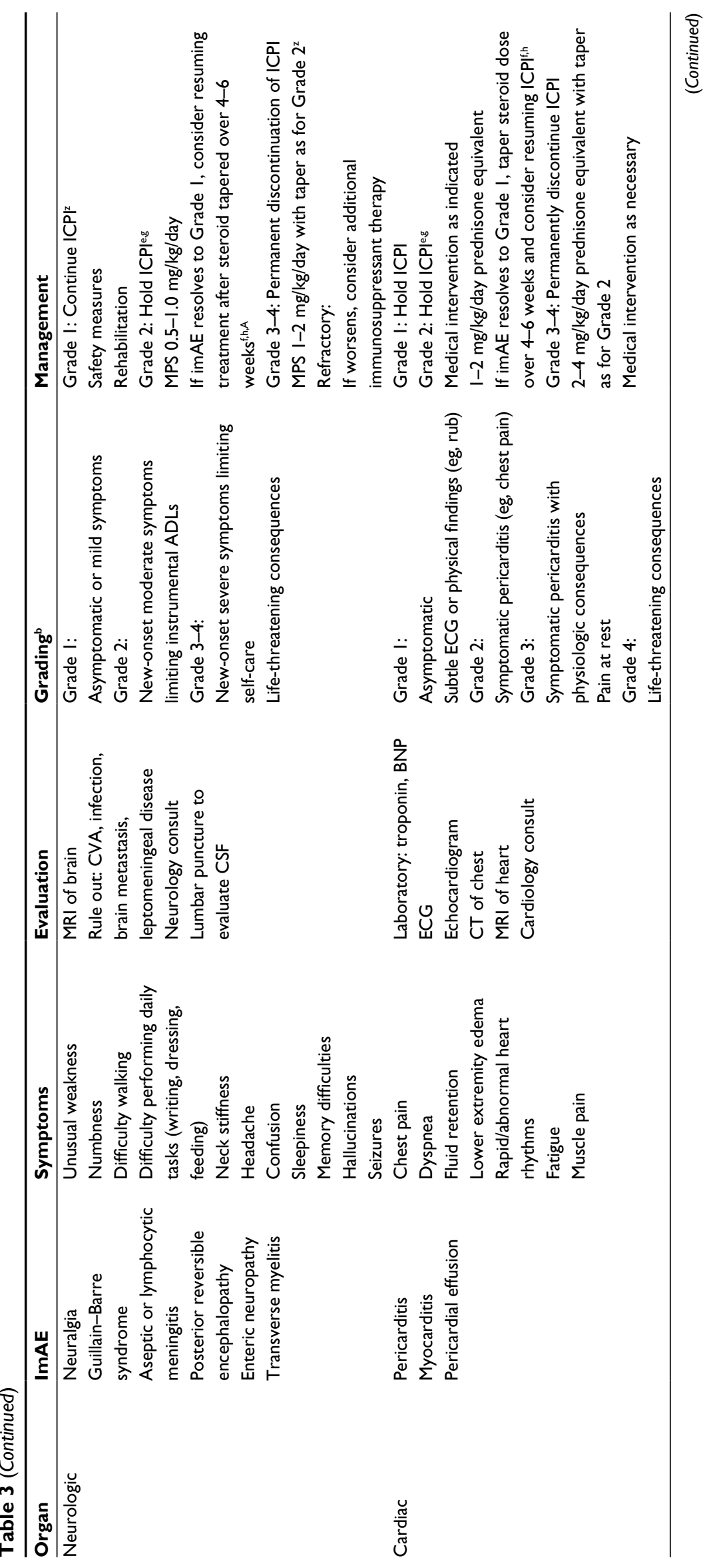




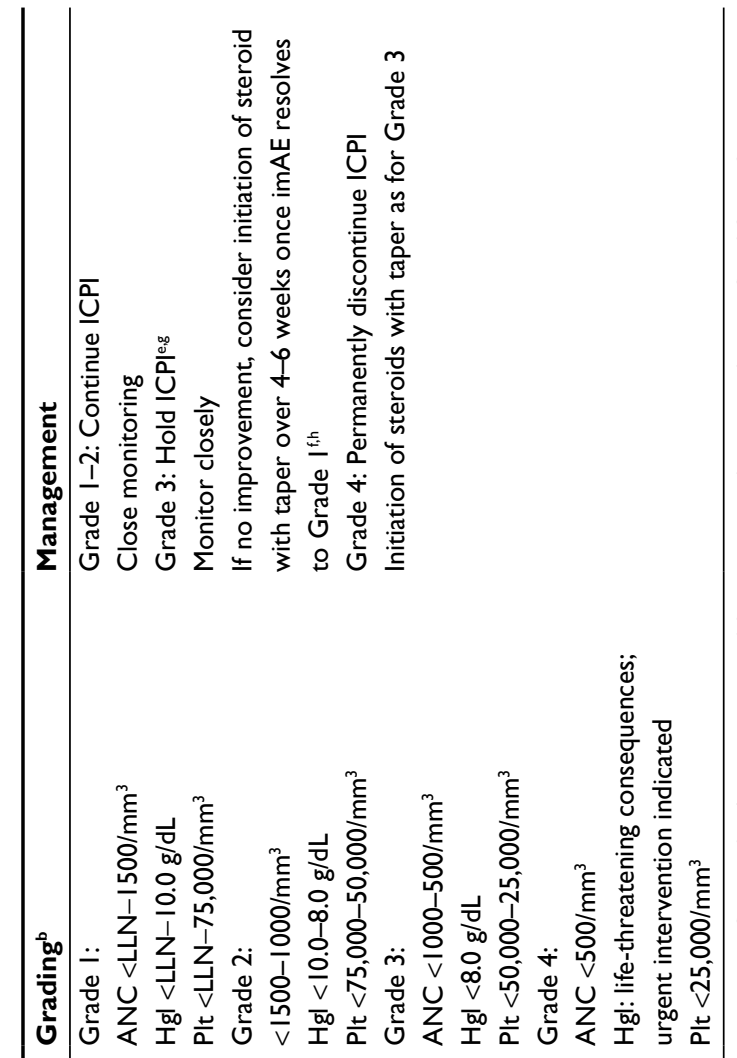

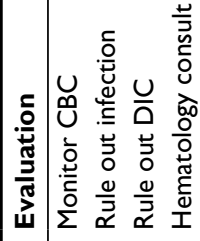
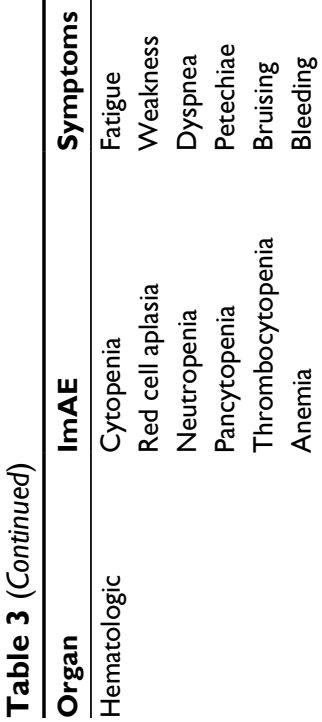

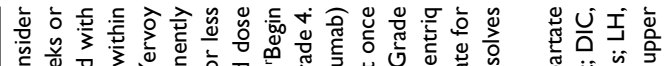

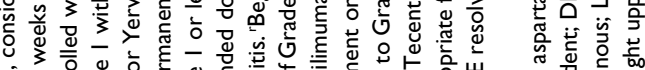

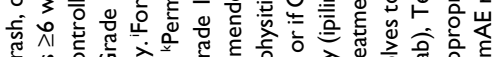

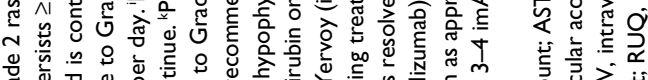

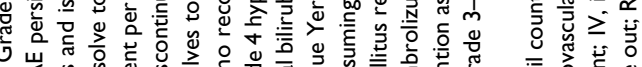

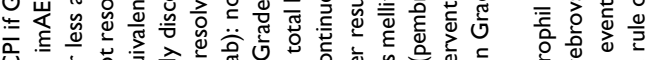

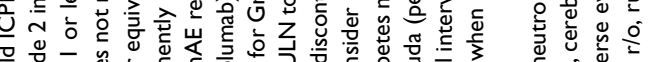

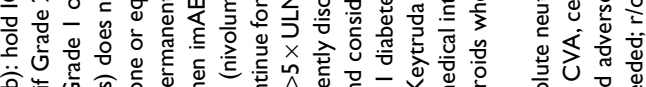

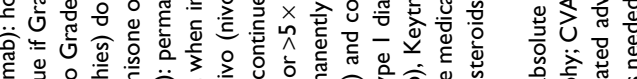

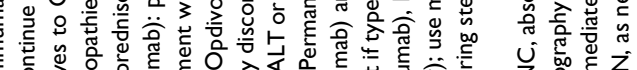

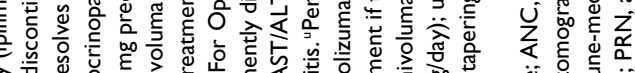

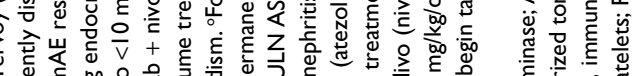

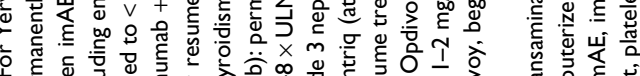

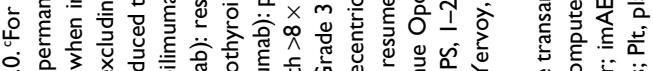

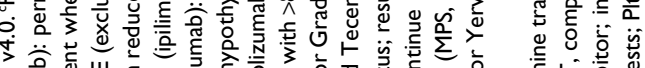

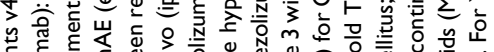

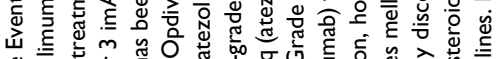

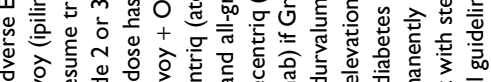

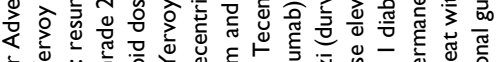

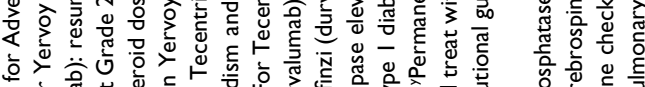

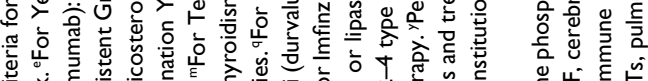

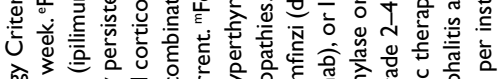

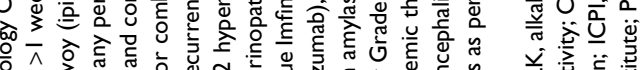

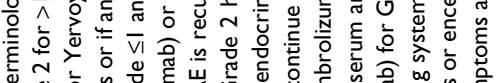

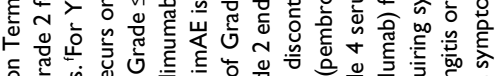

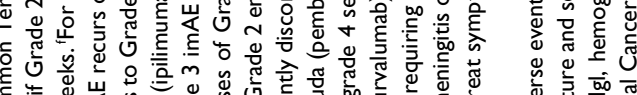

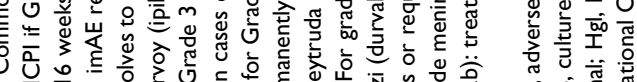
U一

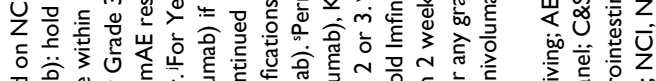

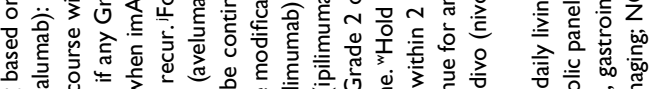
$\begin{array}{llll} & \\ 0\end{array}$ $\begin{array}{llll} & \\ 0 & & \\ 0\end{array}$

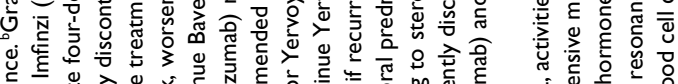
$\begin{array}{lll} & \\ 0\end{array}$

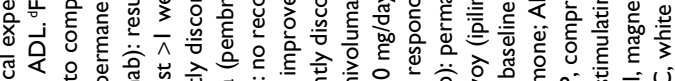

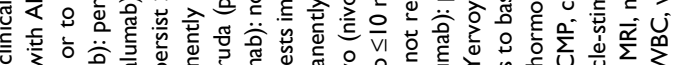

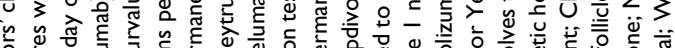

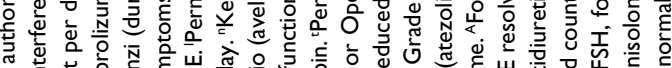

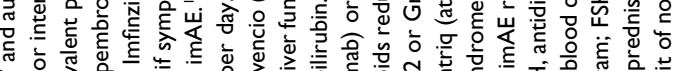

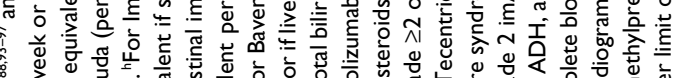

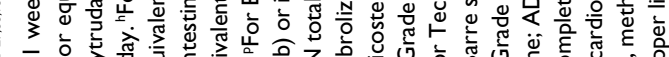

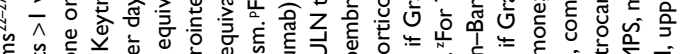

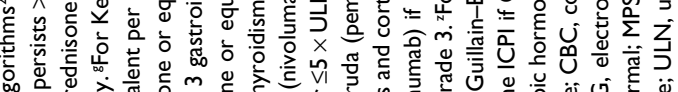

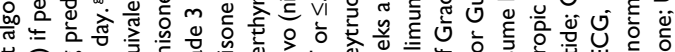

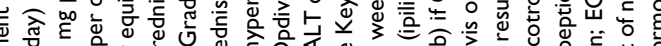

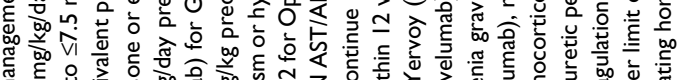

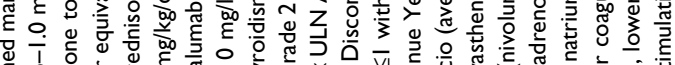

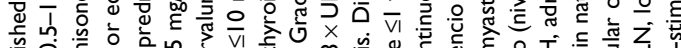

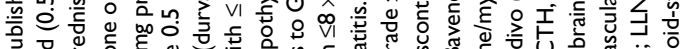

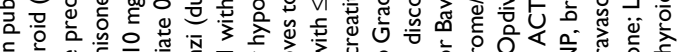

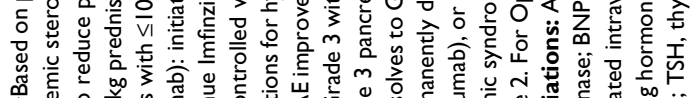

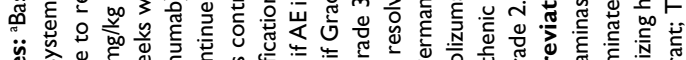

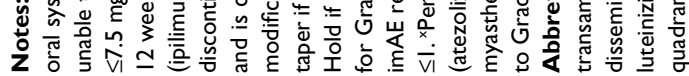




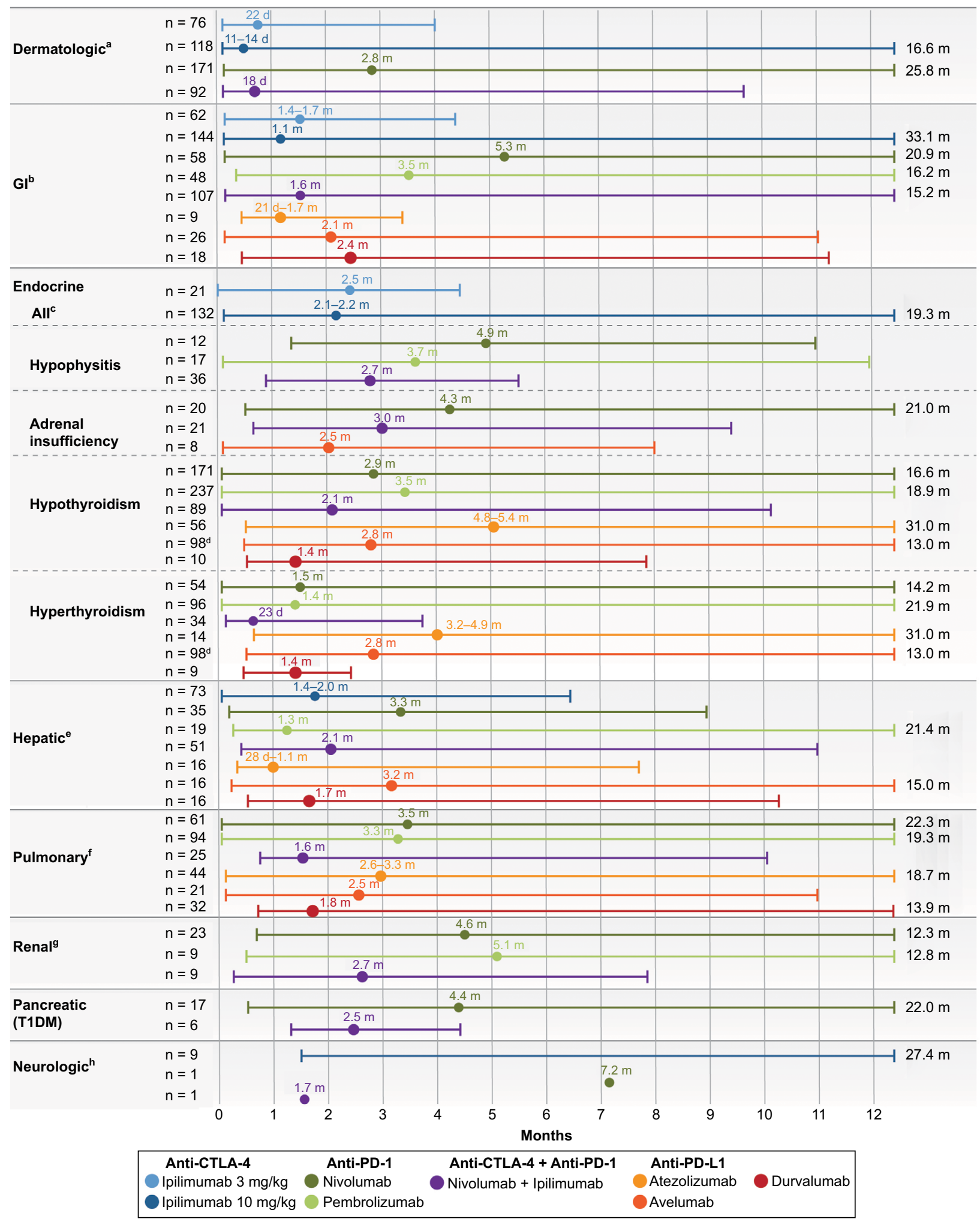

Figure I Time to onset of immune-mediated toxicities (median and range). ${ }^{22-27}$

Notes: Onset patterns of imAEs in patients receiving ICPI treatment by organ system and target pathway: CTLA-4 (ipilimumab), PD-I (nivolumab, pembrolizumab), and PD-LI (atezolizumab, avelumab, and durvalumab). ${ }^{a}$ Dermatitis in ipilimumab studies; immune-mediated rash in nivolumab and nivolumab + ipilimumab studies. ${ }^{b}$ Enterocolitis in ipilimumab studies; colitis in nivolumab, pembrolizumab, avelumab, and nivolumab + ipilimumab studies; colitis or diarrhea in atezolizumab and durvalumab studies. Includes hypopituitarism, adrenal insufficiency, hypothyroidism, hyperthyroidism, hypogonadism, thyroiditis, Cushing's syndrome, and Graves' ophthalmopathy. 'Hypothyroidism and hyperthyroidism are combined for avelumab. ${ }^{\text {eHepatitis. }}{ }^{\text {Pneumonitis. }}{ }^{\mathrm{g} N e p h r i t i s}$ or renal dysfunction in nivolumab and nivolumab + ipilimumab studies; nephritis in pembrolizumab studies. " Neuropathy in ipilimumab studies and encephalitis in nivolumab and nivolumab + ipilimumab studies.

Abbreviations: $\mathrm{d}$, days, $\mathrm{GI}$, gastrointestinal; ICPI, immune checkpoint inhibitor; imAEs, immune-mediated adverse events; m, months; TIDM, type I diabetes mellitus. 
durvalumab, $2 \%{ }^{59}$ ), and $44-45 \%$ of patients receiving combination anti-CTLA-4 and anti-PD-1 therapy with ipilimumab and nivolumab. ${ }^{4,9}$ Colitis has been observed in $7-16 \%$ of patients receiving anti-CTLA-4 therapy (ipilimumab: $\left.3 \mathrm{mg} / \mathrm{kg}, 7-12 \% ;{ }^{4,9,39,42} 10 \mathrm{mg} / \mathrm{kg}, 16 \%{ }^{40}\right), 1-3 \%$ of patients treated with anti-PD-1/PD-L1 antibodies (1\% for nivolumab, 4,6,11,41,62 atezolizumab, ${ }^{7,13,17,44}$ and durvalumab; 59 avelumab, 2\% ${ }^{26}$ pembrolizumab, $1-3 \% 0^{2,16,18,20,42,43}$ ), and $12-18 \%$ of patients treated with combination anti-CTLA-4 and anti-PD-1 therapy (ipilimumab + nivolumab). ${ }^{4,9}$ Rates of Grade 3/4 diarrhea or colitis are low $(\leq 4 \%)$ in patients receiving anti-PD-1 or anti-PD-L1 monotherapy, 2,4,6,7,10,11,13,15-17,20,41-44,50,51,59,60,62 but tend to be higher in patients treated with anti-CTLA-4 monotherapy (ipilimumab, $2-11 \%)^{4,9,39,40,42}$ or combination anti-CTLA-4 and anti-PD-1 therapy with nivolumab and ipilimumab (8-13\%)., The median onset of immune-mediated diarrhea and/or colitis ranges from 21 days to 5.3 months in patients treated with ICPIs in clinical registration studies (Figure 1). ${ }^{22-27}$ Deaths from intestinal perforation from colitis have been reported at very low rates $(<1 \%)$ in anti-CTLA-4 monotherapy studies at both $3 \mathrm{mg} / \mathrm{kg}$ and $10 \mathrm{mg} / \mathrm{kg}$ doses. ${ }^{22,40}$

\section{Endocrine}

Autoimmune endocrinopathies (predominantly Grade 1 or 2) have been reported in patients treated with ICPIs in clinical studies, including hypothyroidism, hyperthyroidism, thyroiditis, hypophysitis (pituitary inflammation), and adrenal insufficiency. ${ }^{22-27}$ Rates of all-grade endocrinopathies are generally low in patients receiving anti-PD-1/PD-L1 monotherapy, with $<10 \%$ of patients experiencing each individual endocrinopathy. ${ }^{23-27}$ Higher rates are reported in patients treated with anti-CTLA-4 therapy either as monotherapy (ipilimumab $3 \mathrm{mg} / \mathrm{kg}, 8-15 \% ; 4,9,39$ ipilimumab $10 \mathrm{mg} / \mathrm{kg}, 38 \%{ }^{40}$ ) or in combination with anti-PD-1 therapy (ipilimumab + nivolumab, 30-31\% $0^{4,9}$ ). Rates of Grade 3/4 endocrinopathies are generally low in patients receiving ICPI monotherapy (anti-CTLA-4: ipilimumab $3 \mathrm{mg} / \mathrm{kg}, 1.8 \%$; anti-PD-1/PD-L1: nivolumab, pembrolizumab, atezolizumab, avelumab, or durvalumab, $<1 \% 0^{4,24-27}$ for each individual endocrinopathy); however, higher rates have been reported with high-dose anti-CTLA-4 (ipilimumab $10 \mathrm{mg} / \mathrm{kg}, 8 \%)^{22}$ and combination anti-CTLA-4 and anti-PD-1 (ipilimumab + nivolumab, 5\%). ${ }^{4,9}$ Most cases of immune-mediated hypothyroidism can be adequately treated with hormone replacement, and ICPI therapy can be continued.

Hypophysitis and thyroid dysfunction are the most common endocrine imAEs associated with ICPI treatment.

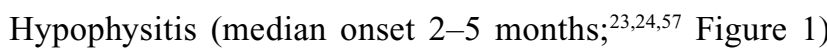

rarely occurred in patients treated with anti-PD-1 or antiPD-L1 monotherapy in clinical studies $(<1 \%$ for nivolumab, pembrolizumab, atezolizumab, or durvalumab), ${ }^{23-25,27}$ but has been observed in 2-7\% of patients receiving anti-CTLA-4 therapy (ipilimumab) at the $3 \mathrm{mg} / \mathrm{kg}$ dose $\mathrm{e}^{4,9,42}$ and $18 \%$ of patients receiving the $10 \mathrm{mg} / \mathrm{kg}$ dose, ${ }^{40}$ and in $8-13 \%$ of patients treated with combination anti-CTLA-4 and antiPD-1 therapy (ipilimumab + nivolumab). ${ }^{4,9}$ The vast majority of patients who experience Grade $\geq 2$ hypophysitis fail to recover pituitary function and require lifelong hormone replacement therapy. ${ }^{22,57,68}$ Adrenal insufficiency can arise secondary to hypopituitarism $(\leq 1 \%$, anti-PD-1 monotherapy [nivolumab] $^{23}$ or anti-PD-L1 monotherapy [atezolizumab, ${ }^{25}$ avelumab, ${ }^{26}$ durvalumab ${ }^{27}$ ]; 5\%, combination anti-CTLA-4 and anti-PD-1 [ipilimumab + nivolumab] ${ }^{23}$ ), typically manifesting as dehydration, hypotension, hyponatremia, and/or hyperkalemia similar to sepsis syndrome. ${ }^{69}$

Hypothyroidism has been reported in $9 \%$ of patients treated with anti-PD-1 (nivolumab or pembrolizumab) (23,24 $^{24}$ or high-dose anti-CTLA-4 monotherapy (ipilimumab $10 \mathrm{mg} / \mathrm{kg}),{ }^{40}$ in $2-13 \%$ of patients receiving standard-dose anti-CTLA-4 monotherapy (ipilimumab $3 \mathrm{mg} / \mathrm{kg}$ ), ,9,39,42 in $4-5 \%$ of patients treated with anti-PD-L1 antibodies (atezolizumab, 4\%; ${ }^{25}$ avelumab, 5\%; ${ }^{26}$ durvalumab, $6 \%{ }^{27}$ ), and in $15-17 \%$ of patients receiving combination anti-CTLA-4 and anti-PD-1 therapy (ipilimumab + nivolumab). ${ }^{4,9}$ In clinical registration studies, the median onset of hypothyroidism ranged from 1 to 5 months, ${ }^{23-27}$ sometimes following a brief period of hyperthyroidism (Figure 1). Hypothyroidism does not resolve for most patients, resulting in the potential need for long-term hormone supplementation. ${ }^{23-27,47,70}$ Hyperthyroidism, which is less common than hypothyroidism, resolves in the vast majority of patients. ${ }^{71}$

\section{Hepatic}

Hepatotoxicity, including hepatitis and elevated alanine transaminase (ALT)/aspartate transaminase (AST), has been documented in patients treated with ICPIs. ${ }^{57,58}$ In patients treated with anti-CTLA-4 therapy, the rate of hepatic adverse events ranged from $4 \%$ to $9 \%$ (ipilimumab $3 \mathrm{mg} / \mathrm{kg}$ ) $4,9,39$ to $25 \%$ (ipilimumab $10 \mathrm{mg} / \mathrm{kg}$ ), ${ }^{40}$ with Grade $3 / 4$ events occurring in $0 \%$ to $2 \%$ to $11 \%$, respectively. Hepatotoxicity occurred in $2-6 \%(0-3 \%$ Grade $3 / 4)$ of the patients treated with anti-PD-1 monotherapy (nivolumab) $4,6,11,15,41,62$ and in $30-32 \%$ (13-19\% Grade 3/4) of the patients receiving combination anti-CTLA-4 and anti-PD-1 therapy (ipilimumab + nivolumab). ${ }^{4,9}$ Immune-mediated hepatitis, reported in $\leq 2 \%$ of patients treated with ICPI monotherapy ${ }^{23-27,39}$ (excluding ipilimumab $10 \mathrm{mg} / \mathrm{kg}$ dose, 15\%), ${ }^{22}$ typically presents 
at 1-3 months and resolves with steroid treatment in most patients (Figure 1). ${ }^{22-27}$ Although rare, fatal cases of immunemediated hepatitis have occurred with ICPI monotherapy (0.2\%, ipilimumab $3 \mathrm{mg} / \mathrm{kg}^{.22} 0.1 \%$, avelumab; ${ }^{26} 0.5 \%$, durvalumab ${ }^{27}$ ). Elevated ALT/AST with concomitant elevated bilirubin may indicate a more serious hepatic injury. ${ }^{72,73}$

\section{Pulmonary}

Immune-mediated pneumonitis is a rare but potentially serious adverse event, occurring in $<1 \%$ of patients treated with anti-CTLA-4 antibodies (ipilimumab $3 \mathrm{mg} / \mathrm{kg}$ or $10 \mathrm{mg}$ / $\mathrm{kg}$ doses), ${ }^{22}$ in $1-3 \%$ of those receiving anti-PD-1/PD-L1 (nivolumab, pembrolizumab, or atezolizumab, 3\%, ${ }^{23-25}$ avelumab, $1 \% ;{ }^{26}$ durvalumab, $0.5 \%{ }^{27}$ ), and in $6 \%$ of those receiving combination anti-CTLA-4 and anti-PD-1 therapy (ipilimumab + nivolumab). ${ }^{23}$ Immune-mediated pneumonitis has been reported more frequently in patients receiving antiPD-1 therapy (nivolumab or pembrolizumab) for NSCLC $(3-6 \%)^{6,11,16,43,50}$ than for melanoma (1-2\%; Table 2). 2,4,41,42,62,66 Pneumonitis has a median onset ranging from 2 months to 4 months (Figure 1). ${ }^{23-27}$

\section{Rare adverse events}

A wide array of additional imAEs has been observed at low rates $(<2 \%)$ in patients receiving ICPI monotherapy across other organ systems, including renal, pancreatic, ocular, musculoskeletal, neurological, cardiovascular, and hematologic toxicities (Table 3). ${ }^{22-27}$ In general, rates of these imAEs are similar or slightly higher in patients receiving combination anti-CTLA-4 and anti-PD-1 antibodies. ${ }^{23}$

\section{Renal}

Immune-mediated nephritis has been observed at low rates in patients receiving anti-CTLA-4 therapy (ipilimumab, $<1 \%$ ), ${ }^{22}$ anti-PD-1 antibodies (nivolumab, 1.2\%, ${ }^{23}$ pembrolizumab, $<0.3 \%{ }^{24}$ ), anti-PD-L1 antibodies (avelumab, 0.1\%; ${ }^{26}$ durvalumab, $\leq 1 \%{ }^{27}$ ), and combination anti-CTLA-4 and antiPD-1 therapy (ipilimumab + nivolumab; $2.2 \%$ ). ${ }^{23}$ The onset of renal imAEs typically occurs earlier with anti-CTLA-4 therapy (2-3 months) than with anti-PD-1 antibodies (3-10 months). ${ }^{74}$

\section{Pancreatic}

Pancreatic toxicities reported in clinical studies with ICPIs include elevated amylase/lipase, pancreatitis, and type 1 diabetes mellitus. Pancreatitis was observed in $\leq 1 \%$ of patients receiving ICPI monotherapy ${ }^{23-26}$ (excluding anti-CTLA-4 therapy with ipilimumab $10 \mathrm{mg} / \mathrm{kg}, 1.3 \%)^{22}$ or combination anti-CTLA-4 and anti-PD-1 therapy (ipilimumab + nivolumab). ${ }^{23}$ Type 1 diabetes mellitus has occurred at low rates in clinical trials of patients receiving anti-PD-1 antibodies (nivolumab, 0.9\%; pembrolizumab, 0.2\%) ${ }^{23,24}$ and antiPD-L1 antibodies (atezolizumab, avelumab, durvalumab, $\leq 0.3 \%),{ }^{25-27}$ and in $1.5 \%$ of patients treated with combination anti-CTLA-4 and anti-PD-1 therapy (ipilimumab + nivolumab). ${ }^{23}$ Although diabetes mellitus was not observed in clinical trials of anti-CTLA-4 monotherapy (ipilimumab), ${ }^{22}$ a report has described a case of diabetes insipidus associated with anti-CTLA-4 monotherapy (ipilimumab). ${ }^{75}$

\section{Ocular}

Ocular imAEs have been reported at very low rates in clinical studies of ICPI monotherapy ${ }^{22-27}$ or combination anti-CTLA-4 and anti-PD-1 therapy (ipilimumab + nivolumab). ${ }^{23}$ Ocular imAEs included uveitis, keratitis, iritis, scleritis, episcleritis, and conjunctivitis, occurring in $\leq 1 \%$ of patients. $^{22-27}$

\section{Musculoskeletal}

Musculoskeletal imAEs have been reported at low rates in ICPI clinical studies, including polymyalgia rheumatica $(<1 \%)$, myositis $(\leq 1 \%)$, and arthritis $(<2 \%))^{22-24,26,27}$ Although inflammatory arthritis has been reported with ICPI treatment in case series, ${ }^{76,77}$ the rate of this adverse event remains unclear due to inconsistent reporting of inflammatory arthritis in ICPI clinical studies. ${ }^{78}$

\section{Neurologic}

A wide array of neurologic imAEs has been associated with ICPI treatment, including Guillain-Barre syndrome, myasthenia gravis, encephalitis, motor dysfunction, meningitis, demyelination, neuropathy, and nerve paresis. In clinical trials, these neurologic imAEs occurred in $\leq 1 \%$ of patients. ${ }^{22-27} \mathrm{~A}$ recent case series, however, noted a $14 \%$ incidence of neurologic toxicities in patients treated with combination anti-CTLA-4 and anti-PD-1 therapy (ipilimumab + nivolumab). ${ }^{79}$

\section{Cardiovascular}

Cardiovascular imAEs occurred in $\leq 1 \%$ of patients treated with ICPIs in clinical studies, including myocarditis, pericarditis, vasculitis, and heart failure..$^{22-24,26,27}$ Case reports and case series have also documented pericardial effusion, cardiomyopathy, and myocardial fibrosis and suggest that patients with preexisting cardiac pathology may be more susceptible to cardiovascular imAEs with ICPI therapy. ${ }^{80,81}$

\section{Hematologic}

Hematologic imAEs, including hemolytic anemia and thrombocytopenic purpura, occurred in $\leq 1 \%$ of patients treated 
with ICPIs in clinical studies. ${ }^{22,24,26,27}$ Case reports have found hematologic imAEs in patients receiving anti-CTLA-4 or anti-PD-1 monotherapy, as well as combination anti-CTLA-4 and anti-PD-1 therapy (ipilimumab + nivolumab) ${ }^{82-85}$

\section{Monitoring and evaluations of patients receiving ICPIs}

Prior to initiating treatment and periodically thereafter, the following laboratory parameters should be assessed: complete blood count, comprehensive metabolic panel (including kidney, liver, pancreatic, and thyroid function tests), and baseline oxygen saturation (including a "walking oxygen saturation" test to facilitate detection of a decrease in oxygen saturation levels that might warrant further diagnostic imaging). ${ }^{22-27,86}$ Assessment and documentation of baseline symptoms (Table 3 ) will allow providers to identify even subtle changes in the patient's status that might represent an early manifestation of an imAE. In addition, oncology nurses could engage in follow-up telephone calls with patients taking ICPIs. ${ }^{87}$ If specific organ toxicity is suspected, careful evaluation strategies, subspecialty consults, and specialized testing (eg, imaging, bronchoscopy, and colonoscopy) may help rule out other possible causes of dysfunction and delineate the extent of the toxicity to determine optimal management strategies. The National Cancer Institute Common Terminology Criteria for Adverse Events v4.0 ${ }^{88}$ should be used to grade baseline symptoms as well as any new symptoms because evaluation and management change according to this grading. Detailed information on evaluation strategies is provided in Table 3 .

Understanding the typical time of onset for the various imAEs can be helpful, but it is important to note that the range can be quite broad (Figure 1). Due to the variable onset of imAEs, it is critical to conduct ongoing assessment of symptoms during and after treatment. Patient assessment forms can be built into the electronic medical record (EMR) to capture and communicate potential imAEs.

\section{Special considerations for patients with preexisting autoimmune disease}

Although patients with preexisting autoimmune conditions were largely excluded from clinical trials, recent retrospective studies suggest that, with close monitoring, ICPIs can be safely and effectively used in this population. ${ }^{89,90}$ Of the 52 patients with preexisting autoimmune disease included in a recent retrospective study, the objective response rate with anti-PD-1 (nivolumab or pembrolizumab) therapy was 33\%, with $38 \%$ of patients experiencing a flare of their underlying autoimmune condition at a median of 38 days from the first dose of ICPI. ${ }^{90}$ The flares were generally mild, with only two patients permanently discontinuing ICPI treatment due to the flare of their autoimmune disorder..$^{90}$ Four patients permanently discontinued ICPI therapy due to the emergence of imAEs. ${ }^{90}$ Due to the potentially higher risk of side effects and exacerbation of the underlying condition in patients with a history of an autoimmune disease, significant caution should be exercised when considering these patients for treatment with ICPIs. Dosing should occur only after a frank discussion between the health care provider and the patient about the nature of the potential risks and benefits of such therapy.

\section{Management of immune-mediated toxicities}

For the current FDA-approved ICPIs, clinicians should follow published guidelines for the management of imAEs. ${ }^{57,58,91-97}$ These imAE algorithms vary based on the type and grade of toxicity, with some Grade 3 imAEs managed by holding therapy and others by permanent discontinuation of ICPI (Table 3). Depending on the organ system involved and the specific ICPI, some mild-to-moderate imAEs can be managed symptomatically, with the patient remaining on ICPIs, while others require the ICPI dose be held and treatment with corticosteroids until the imAE resolves to Grade 1 (Table 3). In patients with more severe (Grade 3/4 or prolonged Grade 2) imAEs, ICPIs are typically discontinued while imAEs are managed with corticosteroids or, if needed, other immunosuppressant agents such as infliximab or mycophenolate (Table 3). ${ }^{57,58,91-97}$ The occurrence of an imAE, regardless of the need for immunosuppressant therapy, does not appear to impact the efficacy of ICPI treatment. ${ }^{65,98}$ Because ICPI treatment is relatively new, physicians and nurses may find printed materials from product companies, ${ }^{22-27,99}$ publications outlining imAE management, ${ }^{57,58,92,97}$ and online algorithm tools ${ }^{86,93-96,100}$ helpful in determining optimal imAE management strategies for their patients (Table 4). Daily communication with the patient (in person or by phone) can help track the status of an imAE and may reduce the risk of mild imAEs escalating to more serious events. ${ }^{87}$

Patients receiving corticosteroid treatment for an imAE should be closely monitored. For mild imAEs, low doses of steroids are normally utilized (methylprednisolone [MPS] $0.5-1.0 \mathrm{mg} / \mathrm{kg} /$ day intravenously or oral prednisone equivalent), while more severe imAEs require higher steroid doses (MPS $1-4 \mathrm{mg} / \mathrm{kg} /$ day intravenously or oral prednisone equivalent). ${ }^{57,58,91-97}$ Patients with severe imAEs may require hospitalization, particularly if they are hemodynamically unstable. 
Table 4 ICPI imAE management resources

\begin{tabular}{|c|c|}
\hline Resource & URL \\
\hline \multicolumn{2}{|l|}{ Print/online } \\
\hline $\begin{array}{l}\text { Immune-mediated adverse reactions management } \\
\text { guide for Yervoy }{ }^{94}\end{array}$ & www.hcp.yervoy.com/servlet/servlet.FileDownload?file=00Pi000000TUzayEAD \\
\hline $\begin{array}{l}\text { Immune-mediated adverse reactions management } \\
\text { guide for Opdivo monotherapy and Opdivo + } \\
\text { Yervoy }{ }^{95}\end{array}$ & www.opdivohcp.com/servlet/servlet.FileDownload?file=00Pi000000kLoKcEAK \\
\hline Opdivo safety tool 100 & www.opdivosafetytool.com/\#/signs-symptoms-management-imars \\
\hline $\begin{array}{l}\text { A guide to monitoring patients during treatment with } \\
\text { Keytruda }^{93}\end{array}$ & www.keytruda.com/static/pdf/adverse-reaction-management-tool.pdf \\
\hline A nurse's guide to Keytruda 99 & www.keytruda.com/static/pdf/nurse-guide-to-treatment-monitoring.pdf \\
\hline Tecentriq adverse event management brochure ${ }^{96}$ & $\begin{array}{l}\text { www.tecentriq.com/content/dam/gene/tecentriq/Tecentriq-Adverse-Event-Management- } \\
\text { Brochure.pdf }\end{array}$ \\
\hline $\begin{array}{l}\text { The clinicians' guide to managing immune-related } \\
\text { adverse events: an interactive algorithm tool }{ }^{86}\end{array}$ & www.clinicaloptions.com/immuneaetool \\
\hline Yervoy Risk Evaluation Mitigation Survey9l & $\begin{array}{l}\text { www.fda.gov/downloads/drugs/drugsafety/ } \\
\text { postmarketdrugsafetyinformationforpatientsandproviders/ucm249435.pdf }\end{array}$ \\
\hline Imfinzi Immune-Mediated Adverse Events & www.imfinzi.com/content/dam/website-services/us/423-durva0-com/resources/imAE_ \\
\hline Management Handbook ${ }^{97}$ & management_handbook.pdf \\
\hline Lighthouse ${ }^{106}$ & www.lighthouseprogram.com \\
\hline Published literature & \\
\hline $\begin{array}{l}\text { Ipilimumab and its toxicities: a multidisciplinary } \\
\text { approach }^{92}\end{array}$ & www.ncbi.nlm.nih.gov/pubmed/23774827 \\
\hline $\begin{array}{l}\text { Management of immune-related adverse events and } \\
\text { kinetics of response with ipilimumab }{ }^{57}\end{array}$ & www.ncbi.nlm.nih.gov/pubmed/226I4989 \\
\hline $\begin{array}{l}\text { Management of adverse events following treatment } \\
\text { with anti-programmed death-I agents }{ }^{58}\end{array}$ & www.ncbi.nlm.nih.gov/pubmed/2740I894 \\
\hline Prescribing information & \\
\hline Yervoy (prescribing information) ${ }^{22}$ & https://packageinserts.bms.com/pi/pi_yervoy.pdf \\
\hline Opdivo (prescribing information) ${ }^{23}$ & https://packageinserts.bms.com/pi/pi_opdivo.pdf \\
\hline Keytruda (prescribing information) ${ }^{24}$ & www.merck.com/product/usa/pi_circulars/k/keytruda/keytruda_pi.pdf \\
\hline Tecentriq (prescribing information) ${ }^{25}$ & www.gene.com/download/pdf/tecentriq_prescribing.pdf \\
\hline Bavencio (prescribing information) ${ }^{26}$ & www.bavencio.com/en_US/document/Prescribing-Information.pdf \\
\hline Imfinzi (prescribing information) ${ }^{27}$ & www.azpicentral.com/imfinzi/imfinzi.pdf \\
\hline
\end{tabular}

Abbreviations: ICPI, immune checkpoint inhibitor; imAE, immune-mediated adverse event.

In patients with serious imAEs, MPS is typically administered intravenously until the toxicity is stable, after which the patient can be transitioned to oral prednisone..$^{57,58,91-97}$ Once the imAE has resolved to Grade 1 per clinical assessment, steroids should be tapered slowly over approximately 1 month or longer, as tapering steroids too quickly may result in a flare of the imAE. Patients should be monitored weekly during and immediately following the steroid tapering. Often ICPIs can be resumed once the imAE has resolved or stabilized to Grade $1 .{ }^{57,58,91-97}$ In some cases, patients may need to remain on physiologic doses of prednisone $(\leq 10 \mathrm{mg})$ to stabilize imAEs at Grade 1..$^{57,92}$ Patients on prolonged corticosteroid treatment ( $>20 \mathrm{mg}$ prednisone equivalent daily for 4 weeks) may require supportive therapy with a proton pump inhibitor and/or antibiotic prophylaxis. ${ }^{58,101}$ In those patients who require long-term steroid use, evaluation by an endocrinologist is recommended, as additional management such as bone density monitoring may be necessary to evaluate the risk of steroid-induced osteoporosis and diabetes and the need for calcium/vitamin $\mathrm{D}_{3}$ repletion. ${ }^{102}$ In general, if a patient requires $>10 \mathrm{mg} /$ day of prednisone equivalent for $>12$ weeks or if there is a persistent Grade 2 or $3 \mathrm{imAE}$ for $>12$ weeks, then ICPI should be permanently discontinued. ${ }^{57,58,91-97}$ The diagnosis and management of three sample patients with different imAEs are shown in Figure 2, including rash, colitis, and adrenal insufficiency.

\section{Education of patients, caregivers, and health care providers on the signs and symptoms of immune- mediated toxicities}

Most moderate and severe immune-mediated toxicities, if detected and treated early, can be managed effectively with oral or intravenous steroids; in rare steroid-refractory cases, other immunomodulatory agents (eg, infliximab or 


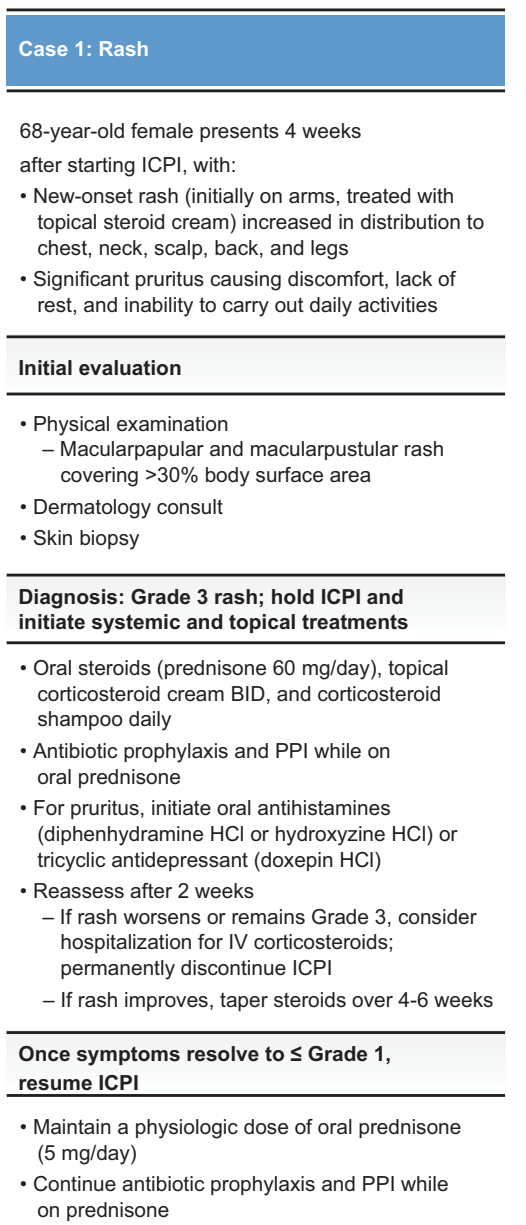

Figure 2 Sample imAE case management. ${ }^{\mathrm{a}}$

Notes: ${ }^{a}$ Cases based on fictitious patients. ${ }^{b}$ lpilimumab + nivolumab. 'Permanently discontinue ICPI therapy in patients with Grade 4 colitis.

Abbreviations: ACTH, adrenocorticotropic hormone; BID, twice daily; BM, bowel movement; CT, computerized tomography; GI, gastrointestinal; HCl, hydrochloride; ICPI, immune checkpoint inhibitor; imAE, immune-mediated adverse event; IV, intravenous; PPI, protein pump inhibitor; TSH, thyroid-stimulating hormone.

mycophenolate mofetil) may be used..$^{57,58}$ It is critical that oncology nurses and physicians treating patients receiving ICPIs familiarize themselves with the signs and symptoms of serious imAEs (Table 3 ).

\section{Patient and caregiver education}

A sound patient management approach includes comprehensive education of patients and caregivers about how to recognize and report suspected symptoms of immune-mediated toxicities. Nurses are frequently the first and primary contact for patients throughout treatment. They can prepare patients with the knowledge to identify the signs and symptoms of imAEs and can highlight the importance of reporting symptoms immediately. Incorporating a multimodal approach to education, including printed materials, online education modules, or educational group sessions, can support patient education and understanding. Where available, patients may benefit from live group education or videos. Toxicity check- lists (available from product companies) may assist patients in recognizing imAE symptoms. Companies' websites offer online educational resources specifically designed for patients and caregivers. Most importantly, patients should be instructed to call their doctor's office if they experience any new, worsening, or otherwise concerning symptoms (even when mild) to maximize early recognition of imAEs.

\section{Education of other health care providers}

As the use of ICPIs becomes ubiquitous across multiple different cancer diagnoses, it is imperative that all health care providers are informed regarding the potential for imAEs in patients being treated with these agents. Several modalities are available to assist other health care providers identify imAEs in this unique group of patients. Patient immunotherapy drug "wallet safety cards" can be a useful tool to alert other providers to be aware of potential imAEs associated with ICPIs, particularly during urgent visits. Health care professionals can 
call the phone number provided on the patient wallet safety card and benefit from peer discussion with the oncology team regarding symptoms, evaluation, and appropriate management. All staff members involved in the telephone triage process who might receive incoming patient phone calls must be educated in the use of the guidelines and in communication and documentation of imAEs. The EMR may also serve as a mechanism to alert other care providers that the patient is receiving immunotherapy. Specific alert mechanisms may be incorporated, such as an alert banner on the chart or a caution alert if a provider attempts to enter an order for an immunemodulating agent. A system alert can be sent to the primary oncology team if the patient presents to the emergency room, is hospitalized, or is evaluated by another discipline.

\section{Conclusion}

Nurses play a critical role in identifying imAEs, educating patients about the importance of the timely reporting of potential imAE symptoms, and assisting in the management and follow-up of patients who develop imAEs while on ICPI therapy. ICPIs are associated with a unique safety profile, characterized by fewer and more tolerable side effects than chemotherapeutic drugs. With additional indications, combination regimens, and late-stage drugs on the horizon, the clinical use of ICPIs is expected to increase. Although most imAEs are mild and easily managed, to ensure optimal patient outcomes, imAEs must be promptly identified and treated to reduce the risk of developing severe imAEs and increase the likelihood that the patient continues to receive the benefits of ICPI treatment.

\section{Acknowledgments}

The authors wish to thank Jennifer Nepo, MS, and Francesca Balordi, PhD, of The Lockwood Group (Stamford, Connecticut, USA) for providing medical writing support, which was according to Good Publication Practice (GPP3) guidelines and funded by AstraZeneca plc (Wilmington, Delaware, USA).

\section{Disclosure}

The authors report no conflicts of interest in this work.

\section{References}

1. Diaz L, Marabelle A, Delord J-P, et al. Pembrolizumab therapy for microsatellite instability high (MSI-H) colorectal cancer (CRC) and non-CRC [abstract and poster at ASCO 2017 Annual Meeting]. J Clin Oncol. 2017;35(Suppl):abstr3071.

2. Ribas A, Puzanov I, Dummer R, et al. Pembrolizumab versus investigator-choice chemotherapy for ipilimumab-refractory melanoma (KEYNOTE-002): a randomised, controlled, phase 2 trial. Lancet Oncol. 2015;16(8):908-918.
3. Seiwert TY, Burtness B, Mehra R, et al. Safety and clinical activity of pembrolizumab for treatment of recurrent or metastatic squamous cell carcinoma of the head and neck (KEYNOTE-012): an open-label, multicentre, phase 1b trial. Lancet Oncol. 2016;17(7):956-965.

4. Larkin J, Chiarion-Sileni V, Gonzalez R, et al. Combined nivolumab and ipilimumab or monotherapy in untreated melanoma. $N$ Engl J Med. 2015;373(1):23-34.

5. Motzer RJ, Escudier B, McDermott DF, et al. Nivolumab versus everolimus in advanced renal-cell carcinoma. $N$ Engl $J$ Med. 2015;373(19):1803-1813.

6. Brahmer J, Reckamp KL, Baas P, et al. Nivolumab versus docetaxel in advanced squamous-cell non-small-cell lung cancer. N Engl J Med. 2015;373(2):123-135.

7. Rosenberg JE, Hoffman-Censits J, Powles T, et al. Atezolizumab in patients with locally advanced and metastatic urothelial carcinoma who have progressed following treatment with platinum-based chemotherapy: a single-arm, multicentre, phase 2 trial. Lancet. 2016;387(10031):1909-1920.

8. Massard C, Gordon MS, Sharma S, et al. Safety and efficacy of durvalumab (MEDI4736), an anti-programmed cell death ligand-1 immune checkpoint inhibitor, in patients with advanced urothelial bladder cancer. J Clin Oncol. 2016;34(26):3119-3125.

9. Hodi FS, Chesney J, Pavlick AC, et al. Combined nivolumab and ipilimumab versus ipilimumab alone in patients with advanced melanoma: 2-year overall survival outcomes in a multicentre, randomised, controlled, phase 2 trial. Lancet Oncol. 2016;17(11):1558-1568.

10. Kaufman HL, Russell J, Hamid O, et al. Avelumab in patients with chemotherapy-refractory metastatic Merkel cell carcinoma: a multicentre, single-group, open-label, phase 2 trial. Lancet Oncol. 2016;17(10):1374-1385.

11. Borghaei H, Paz-Ares L, Horn L, et al. Nivolumab versus docetaxel in advanced nonsquamous non-small-cell lung cancer. $N$ Engl J Med. 2015;373(17):1627-1639.

12. Ferris RL, Blumenschein G Jr, Fayette J, et al. Nivolumab for recurrent squamous-cell carcinoma of the head and neck. $N$ Engl J Med. 2016;375(19): 1856-1867.

13. Rittmeyer A, Barlesi F, Waterkamp D, et al. Atezolizumab versus docetaxel in patients with previously treated non-small-cell lung cancer (OAK): a phase 3, open-label, multicentre randomised controlled trial. Lancet. 2017;389(10066):255-265.

14. Younes A, Santoro A, Shipp M, et al. Nivolumab for classical Hodgkin's lymphoma after failure of both autologous stem-cell transplantation and brentuximab vedotin: a multicentre, multicohort, single-arm phase 2 trial. Lancet Oncol. 2016;17(9):1283-1294.

15. Sharma P, Retz M, Siefker-Radtke A, et al. Nivolumab in metastatic urothelial carcinoma after platinum therapy (CheckMate 275): a multicentre, single-arm, phase 2 trial. Lancet Oncol. 2017;18(3):312-322.

16. Reck M, Rodriguez-Abreu D, Robinson AG, et al. Pembrolizumab versus chemotherapy for PD-L1-positive non-small-cell lung cancer. N Engl J Med. 2016;375(19):1823-1833.

17. Balar AV, Galsky MD, Rosenberg JE, et al; IMvigor210 Study Group. Atezolizumab as first-line treatment in cisplatin-ineligible patients with locally advanced and metastatic urothelial carcinoma: a single-arm, multicentre, phase 2 trial. Lancet. 2017;389(10064):67-76.

18. Balar A, Castellano D, O’Donnell P, et al. Pembrolizumab as firstline therapy in cisplatin-ineligible advanced urothelial cancer: results from the total KEYNOTE-052 study population [abstract and poster presented at ASCO 2017 Genitourinary Cancers Symposium]. J Clin Oncol. 2017;35(Suppl 6S):abstr284.

19. Apolo AB, Infante JR, Balmanoukian A, et al. Avelumab, an antiprogrammed death-ligand 1 antibody, in patients with refractory metastatic urothelial carcinoma: results from a multicenter, Phase Ib Study. J Clin Oncol. 2017;35(19):2117-2124.

20. Bellmunt J, de Wit R, Vaughn DJ, et al; KEYNOTE-045 Investigators. Pembrolizumab as second-line therapy for advanced urothelial carcinoma. N Engl J Med. 2017;376(11):1015-1026. 
21. Langer CJ, Gadgeel SM, Borghaei H, et al; KEYNOTE-021 investigators. Carboplatin and pemetrexed with or without pembrolizumab for advanced, non-squamous non-small-cell lung cancer: a randomised, phase 2 cohort of the open-label KEYNOTE-021 study. Lancet Oncol. 2016;17(11):1497-1508.

22. Bristol-Myers Squibb Company. Yervoy ${ }^{\circledR}$ (ipilimumab) injection [prescribing information]. Princeton, NJ: Bristol-Myers Squibb Company; 2017.

23. Bristol-Myers Squibb Company. Opdivo ${ }^{\circledR}$ (nivolumab) injection [prescribing information]. Princeton, NJ: Bristol-Myers Squibb Company; 2017.

24. Merck \& Company Inc. Keytruda ${ }^{\circledR}$ (pembrolizumab) for injection [prescribing information]. Whitehouse Station, NJ: Merck \& Co., Inc; 2017.

25. Genentech Inc. Tecentriq ${ }^{\circledR}$ (atezolizumab) injection [prescribing information]. South San Francisco, CA: Genentech, Inc.; 2017.

26. EMD Serono Inc. Bavencio ${ }^{\circledR}$ (avelumab) injection, for intravenous use [prescribing information]. Rockland, MD: EMD Serono, Inc. and Pfizer, Inc.; 2017.

27. AstraZeneca Pharmaceuticals LP. Imfinzi ${ }^{\mathrm{TM}}$ (durvalumab) injection, for intravenous use [prescribing information]. Wilmington, DE: AstraZeneca Pharmaceuticals LP; 2017.

28. Nanda R, Chow LQ, Dees EC, et al. Pembrolizumab in patients with advanced triple-negative breast cancer: phase Ib KEYNOTE-012 study J Clin Oncol. 2016;34(21):2460-2467.

29. Muro K, Chung HC, Shankaran V, et al. Pembrolizumab for patients with PD-L1-positive advanced gastric cancer (KEYNOTE-012): a multicentre, open-label, phase 1b trial. Lancet Oncol. 2016;17(6):717-726.

30. Reardon DA, Sampson JH, Sahebjam S, et al. Safety and activity of nivolumab (nivo) monotherapy and nivo in combination with ipilimumab (ipi) in recurrent glioblastoma (GBM): updated results from checkmate-143 [abstract and poster presented at ASCO 2016 Annual Meeting]. J Clin Oncol. 2016;34(15 Suppl):abstr2014.

31. Antonia SJ, Lopez-Martin JA, Bendell J, et al. Nivolumab alone and nivolumab plus ipilimumab in recurrent small-cell lung cancer (CheckMate 032): a multicentre, open-label, phase 1/2 trial. Lancet Oncol. 2016;17(7):883-895.

32. Hamanishi J, Mandai M, Ikeda T, et al. Safety and antitumor activity of anti-PD-1 antibody, nivolumab, in patients with platinum-resistant ovarian cancer. J Clin Oncol. 2015;33(34):4015-4022.

33. Melero I, Sangro B, Yau T, et al. Nivolumab dose escalation and expansion in patients with advanced hepatocellular carcinoma (HCC): the CheckMate 040 study [abstract, poster, and slides presented at ASCO 2017 Gastrointestinal Cancers Symposium]. J Clin Oncol. 2017;35(Suppl 4s):abstr226.

34. Pfizer. Avelumab in previously untreated patients with epithelial ovarian cancer (JAVELIN OVARIAN 100); 2016. Available from: https://clinicaltrials.gov/ct2/show/NCT02718417. NLM identifier: NCT02718417. Accessed April 10, 2017

35. Ribas A, Hanson DC, Noe DA, et al. Tremelimumab (CP-675,206), a cytotoxic $\mathrm{T}$ lymphocyte associated antigen 4 blocking monoclonal antibody in clinical development for patients with cancer. Oncologist. 2007;12(7):873-883.

36. National Comprehensive Cancer Network. Small Cell Lung Cancer (v3.2017); 2017. Available from: https://www.nccn.org/professionals/ physician_gls/pdf/sclc.pdf. Accessed March 15, 2017.

37. Pardoll DM. The blockade of immune checkpoints in cancer immunotherapy. Nat Rev Cancer. 2012;12(4):252-264.

38. McDermott DF, Atkins MB. PD-1 as a potential target in cancer therapy. Cancer Med. 2013;2(5):662-673.

39. Hodi FS, O'Day SJ, McDermott DF, et al. Improved survival with ipilimumab in patients with metastatic melanoma. $N$ Engl $J$ Med. 2010;363(8):711-723.

40. Eggermont AM, Chiarion-Sileni V, Grob JJ, et al. Adjuvant ipilimumab versus placebo after complete resection of high-risk stage III melanoma (EORTC 18071): a randomised, double-blind, phase 3 trial. Lancet Oncol. 2015;16(5):522-530.
41. Robert C, Long GV, Brady B, et al. Nivolumab in previously untreated melanoma without BRAF mutation. $N$ Engl $J$ Med. 2015;372(4):320-330.

42. Robert C, Schachter J, Long GV, et al; KEYNOTE-006 Investigators. Pembrolizumab versus ipilimumab in advanced melanoma. $N$ Engl $J$ Med. 2015;372(26):2521-2532.

43. Herbst RS, Baas P, Kim DW, et al. Pembrolizumab versus docetaxel for previously treated, PD-L1-positive, advanced non-small-cell lung cancer (KEYNOTE-010): a randomised controlled trial. Lancet. 2016;387(10027):1540-1550.

44. Fehrenbacher L, Spira A, Ballinger M, et al; KEYNOTE-006 Investigators. Atezolizumab versus docetaxel for patients with previously treated non-small-cell lung cancer (POPLAR): a multicentre, open-label, phase 2 randomised controlled trial. Lancet 2016;387(10030):1837-1846.

45. Moskowitz C, Zinzani P, Fanale M, et al. Pembrolizumab in relapsed/ refractory classical Hodgkin lymphoma: primary end point analysis of the Phase 2 Keynote-087 Study [presented at ASH 58th Annual Meeting, Dec 3-6; San Diego, CA]. Blood. 2016;128(22):abstr1107.

46. Le DT, Uram JN, Wang H, et al. PD-1 blockade in tumors with mismatch-repair deficiency. NEngl J Med. 2015;372(26):2509-2520.

47. Postow MA, Callahan MK, Wolchok JD. Immune checkpoint blockade in cancer therapy. J Clin Oncol. 2015;33(17):1974-1982.

48. Kumar V, Chaudhary N, Garg M, Floudas CS, Soni P, Chandra AB. Current diagnosis and management of immune related adverse events (irAEs) induced by immune checkpoint inhibitor therapy. Front Pharmacol. 2017;8:49.

49. Abdel-Wahab N, Shah M, Suarez-Almazor ME. Adverse events associated with immune checkpoint blockade in patients with cancer: a systematic review of case reports. PLoS One. 2016;11(7):e0160221.

50. Garon EB, Rizvi NA, Hui R, et al; KEYNOTE-001 Investigators Pembrolizumab for the treatment of non-small-cell lung cancer. N Engl J Med. 2015;372(21):2018-2028.

51. Robert C, Ribas A, Wolchok JD, et al. Anti-programmed-deathreceptor-1 treatment with pembrolizumab in ipilimumab-refractory advanced melanoma: a randomised dose-comparison cohort of a phase 1 trial. Lancet. 2014;384(9948):1109-1117.

52. Topalian SL, Hodi FS, Brahmer JR, et al. Safety, activity, and immune correlates of anti-PD-1 antibody in cancer. $N$ Engl $J$ Med. 2012;366(26):2443-2454.

53. US Food and Drug Administration [webpage on the Internet]. Modification of the Dosing Regimen for Nivolumab; 2016. Available from: www. fda.gov/Drugs/InformationOnDrugs/ApprovedDrugs/ucm520871. htm. Accessed March 24, 2017.

54. Hellmann MD, Rizvi NA, Goldman JW, et al. Nivolumab plus ipilimumab as first-line treatment for advanced non-small-cell lung cancer (CheckMate 012): results of an open-label, phase 1, multicohort study. Lancet Oncol. 2017;18(1):31-41.

55. Long G, Atkinson V, Cebon J, et al. Pembrolizumab (pembro) plus ipilimumab (ipi) for advanced melanoma: results of the KEYNOTE-029 expansion cohort [abstract and slide presentation at ASCO 2016]. J Clin Oncol. 2016;34(Suppl):abstr9506.

56. Rizvi N, Barlesi F, Brahmer J, et al. Phase III, randomized, open-label study of durvalumab (MEDI4736) in combination with tremelimumab or durvalumab alone versus platinum-based chemotherapy in first-line treatment of patients with advanced/metastatic NSCLC: MYSTIC. J Immunother Cancer. 2015;3(Suppl 2):P171.

57. Weber JS, Kahler KC, Hauschild A. Management of immune-related adverse events and kinetics of response with ipilimumab. J Clin Oncol. 2012;30(21):2691-2697.

58. Weber JS, Postow M, Lao CD, Schadendorf D. Management of adverse events following treatment with anti-programmed death-1 agents. Oncologist. 2016;21(10):1230-1240.

59. Powles T, O’Donnell PH, Massard C, et al. Updated efficacy and tolerability of durvalumab in locally advanced or metastatic urothelial carcinoma [abstract and poster presented at ASCO 2017 Genitourinary Cancers Symposium]. J Clin Oncol. 2017;35(6 Suppl):abstr286. 
60. Patel M, Ellerton J, Infante J, Agrawal M. Avelumab in patients with metastatic urothelial carcinoma: pooled results from two cohorts of the phase 1b JAVELIN Solid Tumor trial [abstract and poster presented at ASCO 2017 Genitourinary Cancers Symposium]. J Clin Oncol. 2017;(Suppl 6):abstr330.

61. Apolo A, Ellerton J, Infante J, et al. Updated efficacy and safety of avelumab in metastatic urothelial carcinoma (mUC): pooled analysis from 2 cohorts of the phase $1 \mathrm{~b}$ Javelin solid tumor study [abstract and slide presentation at ASCO 2017 Annual Meeting]. J Clin Oncol. 2017;35(Suppl):abstr4528

62. Weber JS, D’Angelo SP, Minor D, et al. Nivolumab versus chemotherapy in patients with advanced melanoma who progressed after anti-CTLA-4 treatment (CheckMate 037): a randomised, controlled, open-label, phase 3 trial. Lancet Oncol. 2015;16(4):375-384.

63. Belum VR, Benhuri B, Postow MA, et al. Characterisation and management of dermatologic adverse events to agents targeting the PD-1 receptor. Eur J Cancer. 2016;60:12-25.

64. Thebeau M, Rubin K, Hofmann M, Grimm J, Weinstein A, Choi JN. Management of skin adverse events associated with immune checkpoint inhibitors in patients with melanoma: a nursing perspective. J Am Assoc Nurse Pract. 2017;29(5):294-303.

65. Weber JS, Hodi FS, Wolchok JD, et al. Safety profile of nivolumab monotherapy: a pooled analysis of patients with advanced melanoma. J Clin Oncol. 2017;35(7):785-792.

66. Day D, Khoja L, Chen TW-W, Siu LL, Hansen AR. Tumor- and classspecific patterns of immune-related adverse events (irAEs) of immune checkpoint inhibitors (ICIs): a systematic review (SR) [abstract and poster presented at 2016 ASCO Annual Meeting]. J Clin Oncol. 2016;34(15 Suppl):abstr3065.

67. Goldinger SM, Stieger P, Meier B, et al. Cytotoxic cutaneous adverse drug reactions during anti-PD-1 therapy. Clin Cancer Res. 2016;22(16):4023-4029.

68. Postow MA [webpage on the Internet]. ASCO Educational Book: Managing Immune Checkpoint-Blocking Antibody Side Effects; 2015. Available from: http://meetinglibrary.asco.org/content/115000076-156. Accessed April 10, 2017.

69. Villadolid J, Amin A. Immune checkpoint inhibitors in clinical practice: update on management of immune-related toxicities. Transl Lung Cancer Res. 2015;4(5):560-575.

70. Byun DJ, Wolchok JD, Rosenberg LM, Girotra M. Cancer immunotherapy - immune checkpoint blockade and associated endocrinopathies. Nat Rev Endocrinol. 2017;13(4):195-207.

71. Michot JM, Bigenwald C, Champiat S, et al. Immune-related adverse events with immune checkpoint blockade: a comprehensive review. Eur J Cancer. 2016;54:139-148.

72. Reuben A. Hy's law. Hepatology. 2004;39(2):574-578.

73. Bjornsson E. Drug-induced liver injury: Hy's rule revisited. Clin Pharmacol Ther. 2006;79(6):521-528

74. Wanchoo R, Karam S, Uppal NN, et al; Cancer and Kidney International Network Workgroup on Immune Checkpoint Inhibitors. Adverse renal effects of immune checkpoint inhibitors: a narrative review. $\mathrm{Am}$ J Nephrol. 2017;45(2):160-169.

75. Dillard T, Yedinak CG, Alumkal J, Fleseriu M. Anti-CTLA-4 antibody therapy associated autoimmune hypophysitis: serious immune related adverse events across a spectrum of cancer subtypes. Pituitary. 2010;13(1):29-38.

76. Calabrese C, Kirchner E, Kontzias K, Velcheti V, Calabrese LH. Rheumatic immune-related adverse events of checkpoint therapy for cancer: case series of a new nosological entity. RMD Open. 2017;3(1):e000412.

77. Cappelli LC, Gutierrez AK, Baer AN, et al. Inflammatory arthritis and sicca syndrome induced by nivolumab and ipilimumab. Ann Rheum Dis. 2017;76(1):43-50.

78. Cappelli LC, Naidoo J, Bingham CO 3rd, Shah AA. Inflammatory arthritis due to immune checkpoint inhibitors: challenges in diagnosis and treatment. Immunotherapy. 2017;9(1):5-8.

79. Spain L, Walls G, Julve M, et al. Neurotoxicity from immune-checkpoint inhibition in the treatment of melanoma: a single centre experience and review of the literature. Ann Oncol. 2017;28(2):377-385.
80. Yun S, Vincelette ND, Mansour I, Hariri D, Motamed S. Late onset ipilimumab-induced pericarditis and pericardial effusion: a rare but life threatening complication. Case Rep Oncol Med. 2015;2015:794842.

81. Heinzerling L, Ott PA, Hodi FS, et al. Cardiotoxicity associated with CTLA4 and PD1 blocking immunotherapy. J Immunother Cancer. 2016;4:50.

82. Ahmad S, Lewis M, Corrie P, Iddawela M. Ipilimumab-induced thrombocytopenia in a patient with metastatic melanoma. $J$ Oncol Pharm Pract. 2012;18(2):287-292.

83. Palla AR, Kennedy D, Mosharraf H, Doll D. Autoimmune hemolytic anemia as a complication of nivolumab therapy. Case Rep Oncol. 2016;9(3):691-697.

84. Nair R, Gheith S, Nair SG. Immunotherapy-associated hemolytic anemia with pure red-cell aplasia. NEngl JMed. 2016;374(11):1096-1097.

85. Shiuan E, Beckermann KE, Ozgun A, et al. Thrombocytopenia in patients with melanoma receiving immune checkpoint inhibitor therapy. J Immunother Cancer. 2017;5:8.

86. Weber JS [webpage on the Internet]. The Clinicians' Guide to Managing Immune-Related Adverse Events: An Interactive Algorithm Tool; 2016. Available from: http://www.clinicaloptions.com/Oncology/ Treatment \%20Updates/Immune\%20Related\%20AEs/Algorithm\%20 Tool/Interactive_Algorithm_Tool.aspx. Accessed December 1, 2016.

87. Ledezma B, Heng A. Real-world impact of education: treating patients with ipilimumab in a community practice setting. Cancer Manag Res. 2014;6:5-14.

88. National Cancer Institute. Common Terminology Criteria for Adverse Events (v4.0); 2010. Available from: https://evs.nci.nih.gov/ftp1/ CTCAE/CTCAE_4.03_2010-06-14_QuickReference_8.5x11.pdf. Accessed March 15, 2017.

89. Johnson DB, Sullivan RJ, Ott PA, et al. Ipilimumab therapy in patients with advanced melanoma and preexisting autoimmune disorders. JAMA Oncol. 2016;2(2):234-240.

90. Menzies AM, Johnson DB, Ramanujam S, et al. Anti-PD-1 therapy in patients with advanced melanoma and preexisting autoimmune disorders or major toxicity with ipilimumab. Ann Oncol. 2017;28(2):368-376.

91. US Food and Drug Administration. Yervoy ${ }^{\mathrm{TM}}$ (ipilimumab) Risk Evaluation and Mitigation Strategy (REMS); 2012. Available from: http:// www.fda.gov/downloads/drugs/drugsafety/postmarketdrugsafetyinformationforpatientsandproviders/ucm249435.pdf. Accessed October $1,2016$.

92. Fecher LA, Agarwala SS, Hodi FS, Weber JS. Ipilimumab and its toxicities: a multidisciplinary approach. Oncologist. 2013;18(6): 733-743.

93. Merck \& Company Inc. A Guide to Monitoring Patients during Treatment with Keytruda; 2017. Available from: https://www.keytruda.com/static/ pdf/adverse-reaction-management-tool.pdf. Accessed March 29, 2017.

94. Bristol-Myers Squibb. Yervoy Immune-Mediated Adverse Reactions Management Guide; 2015. Available from: http://www.hcp.yervoy. com $/$ servlet/servlet.FileDownload?file=00Pi000000TUzayEAD. Accessed March 24, 2017.

95. Bristol-Myers Squibb. Opdivo Immune-Mediated Adverse Reactions Management Guide; 2017. Available from: http://www.opdivohcp. $\mathrm{com} / \mathrm{servlet} / \mathrm{servlet}$.FileDownload?file $=00 \mathrm{Pi} 000000 \mathrm{kLoKcEAK}$. Accessed March 24, 2017.

96. Genentech Inc. Managing Select Tecentriq Immune-Related Adverse Events; 2016. Available from: www.tecentriq.com/content/dam/ gene/tecentriq/Tecentriq-Adverse-Event-Management-Brochure.pdf. Accessed December 8, 2016.

97. AstraZeneca Pharmaceuticals LP. Imfinzi Adverse Events Management Handbook; 2017. Available from: https:/www.imfinzi.com/content/ dam/website-services/us/434-imfinzi-com/hcp/pdf/imAE_management_handbook.pdf. Accessed July 13, 2017.

98. Horvat TZ, Adel NG, Dang TO, et al. Immune-related adverse events, need for systemic immunosuppression, and effects on survival and time to treatment failure in patients with melanoma treated with ipilimumab at memorial Sloan Kettering Cancer Center. J Clin Oncol. 2015;33(28):3193-3198. 
99. Merck \& Company Inc. A Nurse's Guide to Keytruda; 2016. Available from: https://www.keytruda.com/static/pdf/nurse-guide-to-treatmentmonitoring.pdf. Accessed March 17, 2017.

100. Bristol-Myers Squibb [webpage on the Internet]. The Opdivo Safety Tool; 2016. Available from: https://www.opdivosafetytool.com/\#/ superhome. Accessed March 17, 2017.

101. Luke JJ, Ott PA. PD-1 pathway inhibitors: the next generation of immunotherapy for advanced melanoma. Oncotarget. 2015;6(6):3479-3492.

102. Briot K, Cortet B, Roux C, et al; Bone Section of the French Society for Rheumatology (SFR) and Osteoporosis Research and Information Group (GRIO). 2014 update of recommendations on the prevention and treatment of glucocorticoid-induced osteoporosis. Joint Bone Spine. 2014;81(6):493-501.
103. FDA approves Merck’s Keytruda ${ }^{\circledR}$ (pembrolizumab) for adult and pediatric patients with classical Hodgkin lymphoma (cHL) refractory to treatment, or who have relapsed after three or more prior lines of therapy [press release]; 2017.

104. US FDA accepts first biologics license application for AstraZeneca's durvalumab in bladder cancer [press release]; 2016.

105. Postow MA, Chesney J, Pavlick AC, et al. Nivolumab and ipilimumab versus ipilimumab in untreated melanoma. $N$ Engl $J$ Med. 2015;372(21):2006-2017.

106. AstraZeneca Pharmaceuticals LP [homepage on the Internet]. Lighthouse Program; 2017. Available from: https://www.lighthouseprogram. $\mathrm{com} /$. Accessed May 3, 2017.

\section{Publish your work in this journal}

ImmunoTargets and Therapy is an international, peer-reviewed open access journal focusing on the immunological basis of diseases, potential targets for immune based therapy and treatment protocols employed to improve patient management. Basic immunology and physiology of the immune system in health, and disease will be also covered. In addition, the journal will focus on the impact of manage-

\section{Dovepress}

ment programs and new therapeutic agents and protocols on patient perspectives such as quality of life, adherence and satisfaction. The manuscript management system is completely online and includes a very quick and fair peer-review system, which is all easy to use. Visit http://www.dovepress.com/testimonials.php to read real quotes from published authors. 